\title{
Materiales inéditos del asentamiento fortificado de Valencia do Sil (Vilamartín de Valdeorras, Ourense)
}

\author{
Unpublished material from the fortified settlement of Valencia do Sil \\ (Vilamartín de Valdeorras, Ourense)
}

http://dx.doi.org/10.15304/gall.38.5949

\section{Carlos Tejerizo-García}

Universidad del País Vasco/Euskal Herriko Unibertsitatea

carlosteje@gimail.com

http://orcid.org/0000-0001-9479-2720

\author{
Agustina Scaro \\ Consejo Nacional de Investigaciones Científicas y Técnicas, Argentina \\ eowyn939@gmail.com
}

Eduardo Daflon

Universidade Federal Fluminense, Brasil

ec.daflon@gmail.com

\begin{abstract}
Resumen
En este artículo presentamos un conjunto de materiales inéditos procedentes del yacimiento arqueológico de Valencia do Sil (Vilamartín de Valdeorras, Ourense) almacenados en las dependencias del Concello de $\mathrm{O}$ Barco de Valdeorras. Este material proviene de diversas intervenciones llevadas a cabo sobre el sitio desde los años 60 hasta, probablemente, los años 80. Su interés radica no solo en su volumen, sobre todo en lo que respecta al conjunto cerámico, sino por la valiosa información que proporciona sobre un yacimiento conocido de antiguo por la historiografía pero del que apenas se tenía información.
\end{abstract}

Palabras clave: Tardorromanidad; Época Sueva; Valencia do Sil; Cerámica; Asentamientos fortificados; Valle del río Sil.

\begin{abstract}
We present in this paper the analyses of some unpublished archaeological record from the site of Valencia do Sil (Vilamartín de Valdeorras, Ourense). This material is currently stored in the dependencies of the Council of $\mathrm{O}$ Barco de Valdeorras, and it comes from a varied set of archaeological interventions which took place from the 60 s until, probably, the 80 s. This revision is not only interesting for its significant quantity, especially regarding the ceramic assemblages, but also for the valuable information it gives on this site. A site that was previously known by historiography but of which there was a lack of information.
\end{abstract}

Keywords: Late Roman; Suevic period; Valencia do Sil; Pottery; Fortified settlements; River Sil valley. 


\section{INTRODUCCIÓN ${ }^{1}$}

El valle del río Sil en la zona de la comarca de Valdeorras, con toda su belleza, esconde una curiosa paradoja: si bien es un entorno repleto de yacimientos arqueológicos especialmente señeros para la historia del noroeste peninsular, es muy poca la información publicada que se tiene de la mayoría de ellos (una excepción en RODRÍGUEZ COLMENERO, FERRER SIERRA, y GARCÍA TATO 2009). Ello es consecuencia de una historiografía muy particular, jalonada de intervenciones arqueológicas de pioneros grupos locales, varios expolios y actividades de detectoristas, la construcción de la Nacional-120 o la histórica plantación de los viñedos que ahora forman parte intrínseca del paisaje de una comarca dedicada al vino. Todos estos hitos generaron una importante cantidad de datos arqueológicos, si bien muy dispersos y en ocasiones difíciles de rastrear.

En el contexto de un proyecto de investigación sobre la época tardoimperial y sueva, cuyo objetivo principal es el análisis de las transformaciones sociales y políticas entre el fin del Imperio Romano y la Alta Edad Media en el interior del antiguo territorio de Gallaecia $^{2}$, pudimos hacer una primera prospección arqueológica intensiva del territorio con el objetivo de reunir toda la información disponible sobre distintos yacimientos de la zona datados en este período histórico. Así, se pudo hacer una primera revisión de los datos disponibles e inéditos de yacimientos previamente conocidos en la historiografía como los de Penadominga, Quiroga o Proendos (FERNÁNDEZ PEREIRO, TEJERIZO GARCÍA, RODRÍGUEZ GONZÁLEZ, LIXÓ GÓMEZ, y CARVAJAL CASTRO 2017).

Entre ellos, uno de los yacimientos que destacó por su mayor potencialidad arqueológica fue el de Valencia do Sil, situado en el actual municipio de Vilamartín de Valdeorras, del que pudimos hacer una primera propuesta planimétrica así como algunas primeras consideraciones sobre su secuencia de ocupación y función en el contexto del fin del Imperio Romano. De hecho, durante aquellos trabajos tuvimos la oportunidad de revisar un pequeño conjunto de materiales depositados en el Museo de Ourense, que nos permitió hacer una primera propuesta de ocupación cronológica del sitio que situábamos entre el siglo IV y el siglo VI d.n.e. con una posible, si bien dudosa, fase prehistórica.

Ya en aquella publicación se hacía mención a un conjunto de materiales asociados al yacimiento de Valencia do Sil depositados en los almacenes del municipio de O Barco de Valdeorras proveniente de diversas intervenciones sobre el sitio, pero que no tuvimos la ocasión de revisar entonces. En noviembre de 2018 pudimos realizar una revisión de este material, del que no se tenía constancia en las publicaciones académicas ${ }^{3}$. Dada la

1 Este trabajo ha sido realizado en el marco del Proyecto "Agencia campesina y complejidad sociopolítica en el noroeste de la Península Ibérica en época medieval” (Ministerio de Economía, Industria y Competitividad, AEI/FEDER UE HUM201676094-C4-2-R), del Grupo de Investigación en Arqueología Medieval, Patrimonialización y Paisajes Culturales / Erdi Aroko Arkeologia, Ondaregintza eta Kultur Paisaiak Ikerketa Taldea(Gobierno Vasco, IT1193-19) y del Grupo de Estudios Rurales (Unidad Asociada UPV/EHU-CSIC). Agradecemos a los dos evaluadores externos las aportaciones realizadas, que han mejorado sustancialmente el texto original. Los errores son obra exclusiva de los autores.

2 Proyecto postdoctoral financiado por la Xunta de Galiza: "Sputnik Labrego. Resiliencia e resistencia da sociedade labrega galega en "momentos de perigo": unha análise antropolóxica e arqueológica na longa duración”. Toda la información puede consultarse en la página web: sputniklabrego.com.

3 Agradecemos al Concello de O Barco de Valdeorras y en especial a Gustavo Docampo todas las facilidades para poder llevar a cabo esta revisión, así como a José Fernández Pérez, “Pepe o das Pedras” por la visita que pudimos hacer al yacimiento durante aquellos días. 
cantidad y relevancia de este material no solo para el conocimiento de este importante yacimiento, sino para el análisis del período tardoimperial y suevo del interior de la antigua provincia romana de Gallaecia, consideramos oportuna su publicación. En este artículo se presentan los resultados de este análisis, precedido de una síntesis de las diversas intervenciones que se realizaron en el yacimiento de Valencia do Sil. En este análisis, por su importancia dentro del conjunto analizado, se presta especial atención al material cerámico, si bien se presenta toda la evidencia arqueológica disponible. Finalmente, se realizarán algunas consideraciones en relación a la relevancia del sitio en el contexto geográfico e histórico en el que se enmarca.

\section{El yacimiento de VAlencia do Sil}

El castro de Valencia do Sil se sitúa en el Concello de Vilamartín de Valdeorras, en la parroquia de San Bernabé, en un espolón de base geológica de esquisto y cuarcita sobre la margen izquierda del río Sil, a unos 450 m de altitud, siendo sus coordenadas (ETRS89; huso 29): $\mathrm{X}=658352 ; \mathrm{Y}=4695874$ (Figura 1). Toda la zona que ocupa el castro tiene una pendiente muy pronunciada en dirección NE-SW, producto de diferentes episodios de derrumbe que, por otro lado, han conservado el yacimiento de forma excepcional. La extensión total del espolón es de 5 ha, pero la zona de ocupación se restringe a unos 4 has. de extensión. Toda esta zona estaría recorrida por la vía romana XVIII o Via Nova, y que pasaría por las cercanías del asentamiento. Esta vía conectaba Bracara Augusta (Braga) con Asturica Augusta (Astorga), atravesando este territorio situado en los márgenes del río Sil (RODRÍGUEZ COLMENERO 1977; RODRÍGUEZ COLMENERO, et al. 2009). Por la descripción consignada en el itinerario de Antonino sabemos que varias mansiones se localizaban en este entorno de Valdeorras, una de las cuales fue relacionada con el yacimiento de "La Cigarrosa" así como a otros restos arqueológicos excavados en el sitio de A Proba, que podrían responder a un asentamiento secundario de época altoimperial (SOTO ARIAS 1993; VEIGA ROMERO 2009).

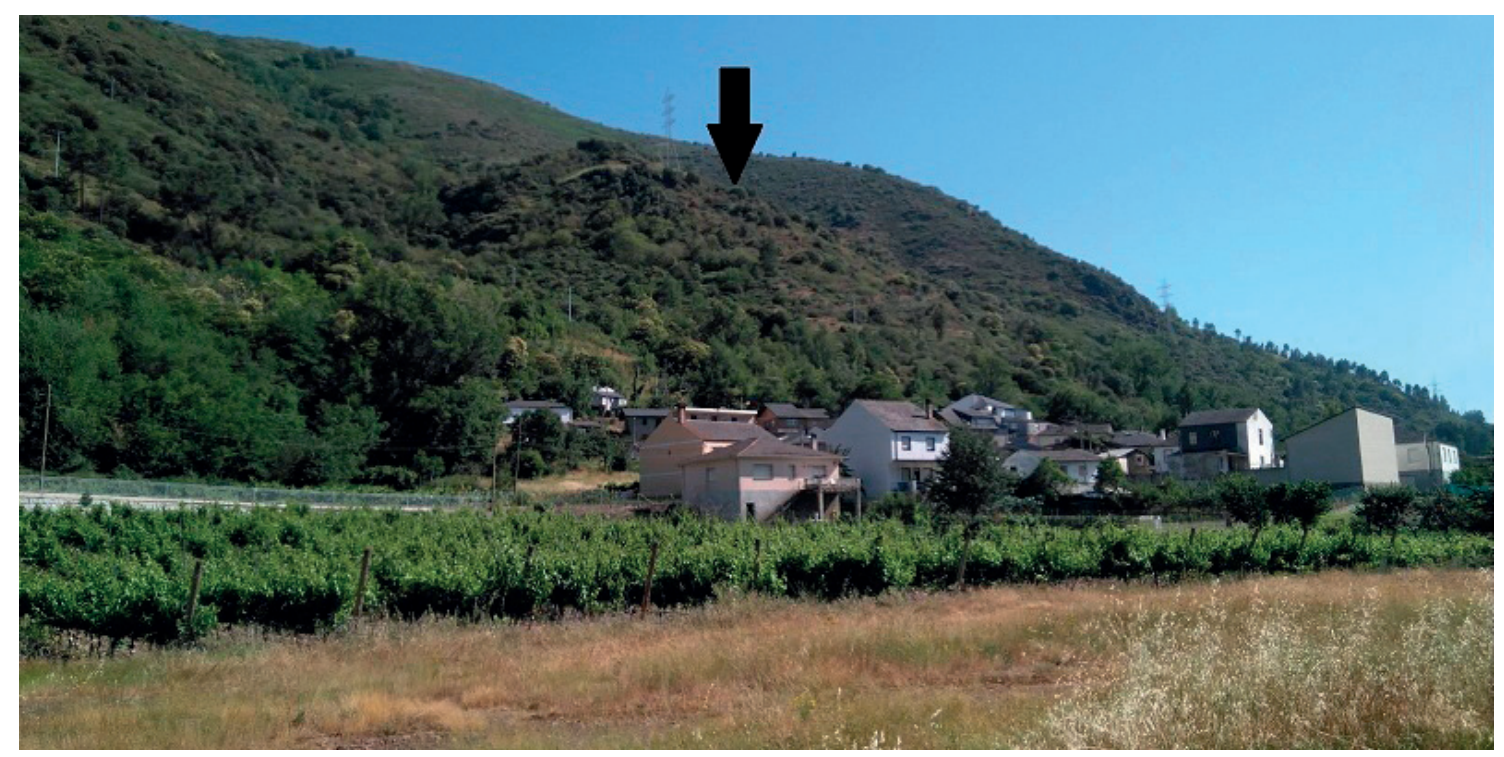

Figura 1. Contexto de Valencia do Sil. En la ladera, el pueblo actual. 
A pesar de la instalación de viñas en un momento indeterminado, posiblemente con un profundo impacto durante el siglo XIX, muy visibles en la fotografía aérea histórica, el sitio arqueológico parece que no fue especialmente alterado por los viñedos, como sí ocurre con otros yacimientos del entorno, como el de Santa María de Mones (Petín) (FERNÁNDEZ PEREIRO, et al. 2017) (Figura 2). A tenor de los restos arqueológicos excavados, parece que los procesos postdeposicionales de corrimiento de tierras, así como la generación de plataformas para la instalación de los viñedos habrían conservado gran parte del yacimiento. Este viñedo, a partir de informaciones orales de los vecinos, parece que fue abandonado antes de las intervenciones arqueológicas sobre el sitio a partir de los años 60. Cabe señalar la presencia de una torre eléctrica de media tensión instalada dentro de los límites del asentamiento, cuya afección sobre el sitio es difícil de valorar, ya que no hubo seguimiento arqueológico durante su instalación.

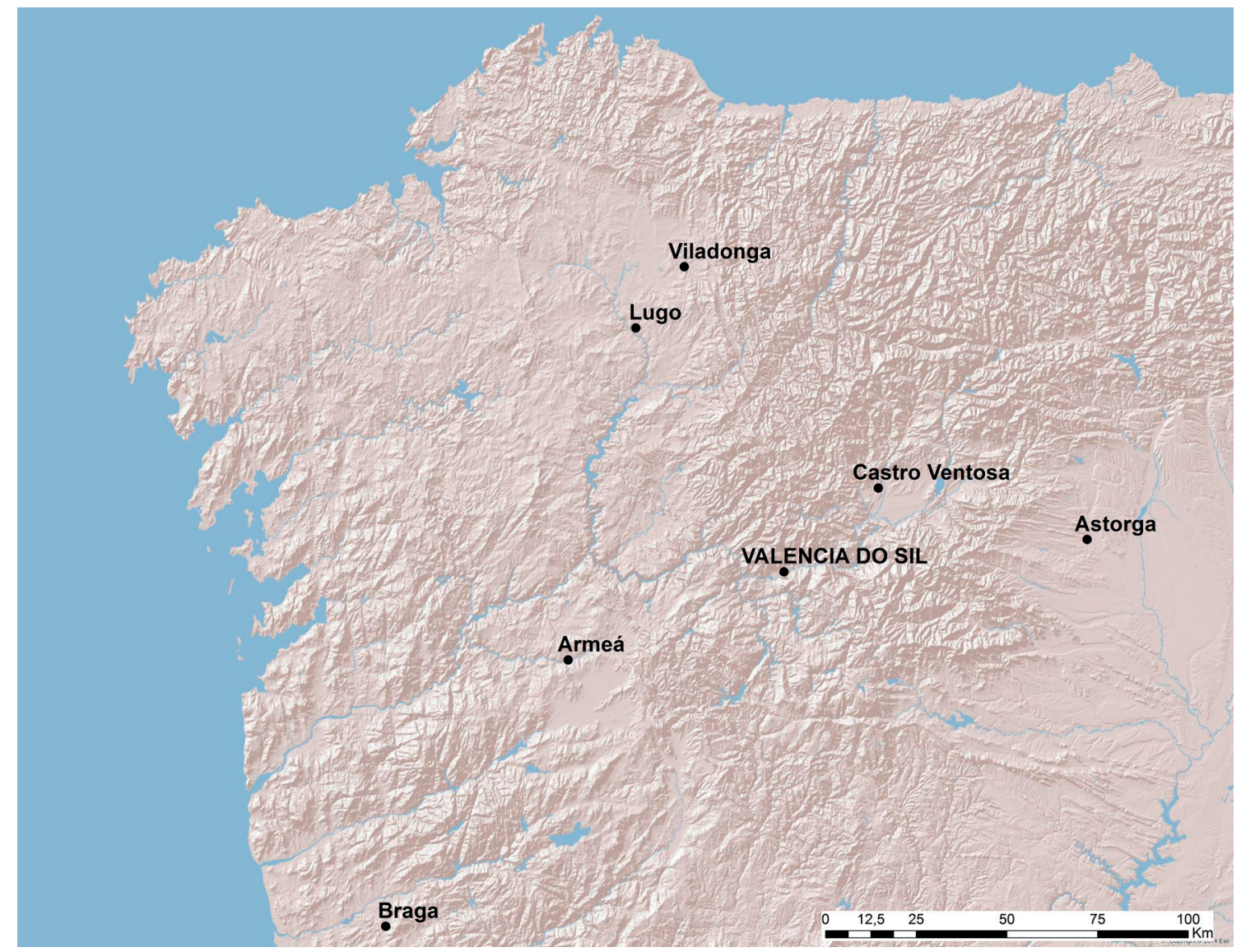

Figura 2. Localización de Valencia do Sil en el contexto de algunos de los principales yacimientos para el estudio de la cerámica del noroeste peninsular en época tardorromana y sueva.

El sitio de Valencia do Sil, si bien era conocido desde inicios del siglo XX, no fue objeto de excavaciones hasta finales de los años 60. Desde entonces, ha sido objeto de numerosas campañas de intervenciones por distintas personas y asociaciones hasta la actualidad. Estas intervenciones se pueden dividir en cuatro grandes etapas:

1. Intervenciones del grupo de "Os Escarbadores". Este grupo se constituyó en los años sesenta por varios vecinos de la localidad de O Barco de Valdeorras. Realizaron varias intervenciones en diversos yacimientos de la zona del río Sil, que 
incluyeron La Cigarrosa o A Proba (VEIGA ROMERO 2009). Igualmente, realizaron varias campañas de excavación en Valencia do Sil, si bien no se conocen las fechas exactas de estas intervenciones, que debieron tener lugar a finales de los años 60 y principios de los años 70, fundamentalmente (MÉNDEZ REVUELTA 1974-1975: 298-299). Contamos con algunas planimetrías (una de ellas datada en septiembre de 1974), así como algunas fotografías de estas intervenciones, algunas datadas en el año 1970-1971 (Figura 3).

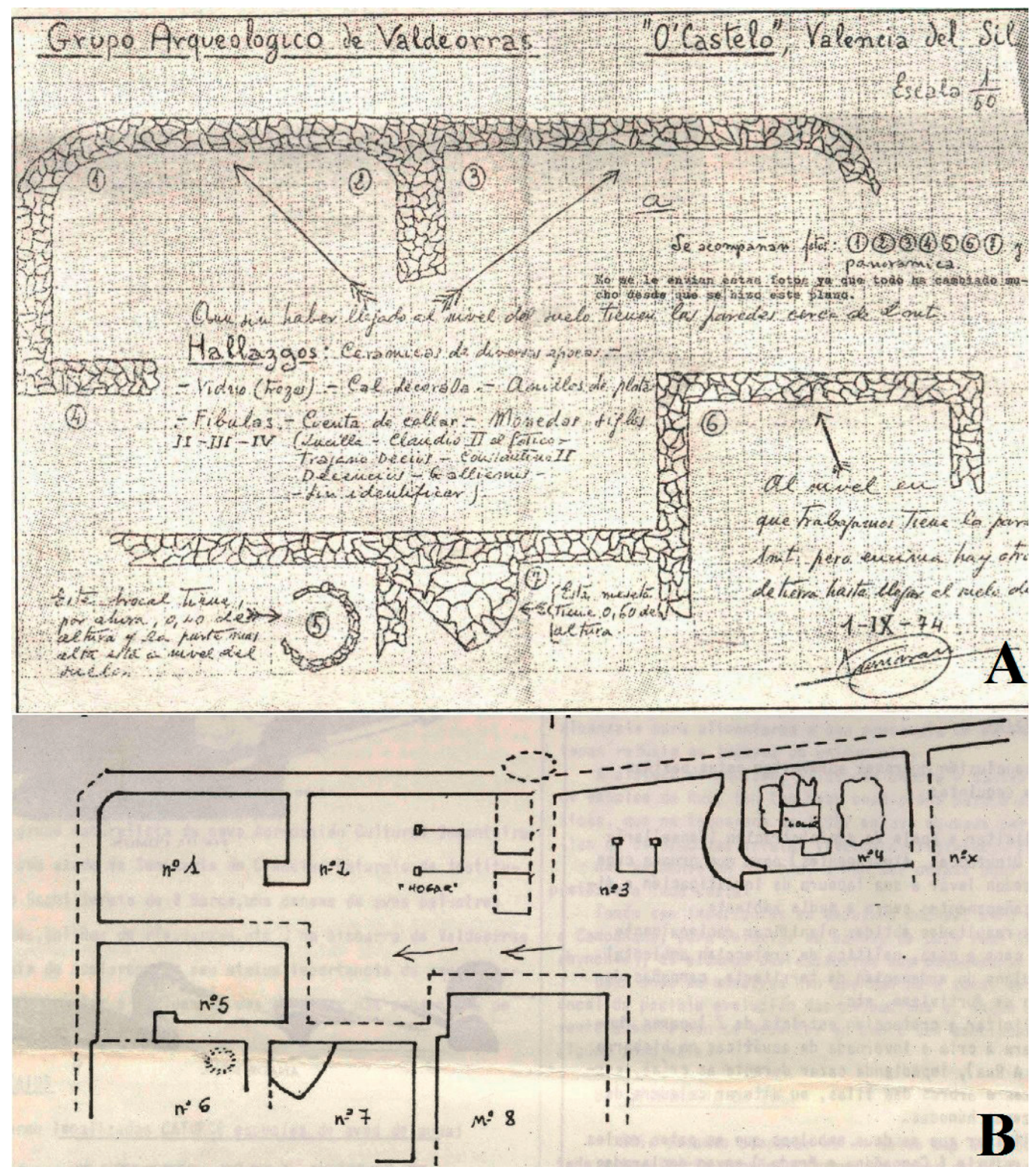

Figura 3 (A y B). Planimetría de las estructuras excavadas por el Grupo Arqueológico de Valdeorras.

2. Intervenciones de un profesor de instituto de Pontevedra de apellido Pájaro. El número concreto de intervenciones es desconocido, así como las fechas en que se produjeron. Sin embargo, en la revisión de las bolsas donde se encontraba el material se localizaron varias etiquetas de papel que consignaban fechas. Concretamente, se localizaron referencias a "agosto 1977", “Agosto 1980 (recogidos en 
limpieza caseta agosto 1984)", “21-6-83”, "agosto 1984” y "agosto 1985”. Entendemos por lo tanto que, al menos, estas excavaciones habrían tenido lugar entre el año 1977 y 1985.

3. Intervenciones clandestinas desde los años 90. En 1992, por iniciativa de José Fernández Pérez, y con apoyo del Concello de Vilamartín de Valdeorras y de la Diputación de Ourense, se realizó una limpieza del sitio que incluyó la colocación de algunos carteles y la realización de visitas guiadas. En el contexto de esta limpieza es cuando se localizaron los restos óseos que fueron objeto de un análisis específico (ver más adelante). Desde entonces se realizaron varias excavaciones clandestinas en el yacimiento, que fueron especialmente significativas en los años 2009-2010, año en que fueron denunciadas y paralizadas. No se conoce el alcance de estos expolios ni la cantidad de material que fue saqueado.

4. En el año 2019, en el contexto de la celebración del 50 aniversario de la formación del grupo de Os Escarbadores, se llevó a cabo una nueva limpieza del sitio por parte de Santiago Ferrer. Durante esta limpieza se recuperó un interesante lote de piezas que están todavía por estudiar.

El material que ha podido ser revisado pertenece, previsiblemente, tanto a las intervenciones llevadas a cabo por el grupo de Os Escarbadores como por el profesor del instituto de Pontevedra. No ha sido posible, sin embargo, contextualizar el conjunto de bolsas de material, desconociendo por tanto su fecha de excavación (salvo en las bolsas anteriormente mencionadas) o la ubicación estratigráfica del material. Esto, sin duda, ha limitado notablemente el alcance del análisis realizado. Todo este material fue almacenado conjuntamente en previsión de ser expuesto en un futuro museo que recogería materiales de diversos yacimientos del entorno de Valdeorras pero que finalmente no se puso en marcha ${ }^{4}$.

De hecho, en el transcurso de este proceso, el Instituto de Estudios Valdeorreses confeccionó un inventario de aquellos objetos que habían recopilado, titulado: "Inventario, de los bienes que en (sic), en propiedad, donaciones y depósito, posee el Museo Arqueológico de Valdeorras”. En él se registran varias entradas referidas a Valencia do Sil, que recopilamos a continuación:

- Donación don Aurelio Blanco Trincado

- Colección recuperada en el Castelo de Valencia del Sil. Esta colección consta de 66 piezas

2. MATERIAL METÁLICO Castelo de Valencia del Sil

- Cuentas de collar en azurita (2 piezas)

- Adornos tipo anillo en bronce (2)

- Sortijas (3)

4 Aunque recientemente se ha vuelto a solicitar por parte del Instituto de Estudios Valdeorreses: http://www.laregion.es/articulo/ valdeorras/instituto-estudios-pide-habilitar-museo-barco/20190309204034859349.html [consultado el 25 de marzo de 2019]

5 Agradecemos a Aurelio Blanco Trincado que nos hiciera llegar una copia de este inventario. 
- Fígulas (sic) (1)

- Varios punzones, punta de flecha, clavos de diversos tipos, remaches en plomo y varios

3. Cerámica Castelo de Valencia del Sil

- Trozo de cerámica con la firma "M a M" (1)

- Trozos de vasijas en reconstrucción y teselas Mosaico Rua

- Pondios de Telar

- Trozos terra sigillata con diversos grabados

- Contrapesos de pesca con rez (sic)

- Varios trozos de cerámica incisa y plástica

- Varios vidrios romanos de Valencia del Sil y la Puebla

- Fondos, asas y bordes ánforas

- Varios trozos de cerámica y clovos (sic) y Terra sigillata de la Puebla

Como se puede comprobar, el número de intervenciones sobre el sitio ha sido muy numerosa. Sin embargo, no existen muchas publicaciones en relación al yacimiento de Valencia do Sil ni referencias al mismo, a pesar de su enorme relevancia arqueológica. Entre estas escasas menciones, cabe señalar la de V. Risco en su apartado de Ourense dentro de la Geografía General del Reino de Galicia de F. Carreras, que señala que "en el término de Valencia hay un castro llamado O Castelo, que conserva algo de sus fortificaciones y en el que se han encontrado trozos de cerámica y objetos de oro" (RISCO 1920: 732 y ss.). Por su parte, F. Bouza adjudica al sitio de Valencia do Sil dos monedas de época sueva, sugiriendo la posibilidad de que en el asentamiento se instalase una ceca durante este período, si bien su interpretación es quizá un poco arriesgada (BOUZA BREY 1953; PLIEGO VÁZQUEZ 2009).

Una de las pocas publicaciones que aborda de forma directa el estudio materiales del sitio viene firmada por C. Méndez, donde analiza algunos fragmentos de sigillata seleccionados del sitio (MÉNDEZ REVUELTA 1974-1975). Según describe la autora, estos fragmentos provendrían de las excavaciones llevadas a cabo en 1970 por el "Grupo Arqueológico de Valdeorras” (es decir, Os Escarbadores) dirigido por Joaquín Gurriarán. Cabe señalar que en este estudio se hace referencia a la aparición de monedas acuñadas en "Cascantum” (Cascante, Navarra) y “dos bronces de Constantino I" (MÉNDEZ REVUELTA 1974-1975: 299; nota 295).

En el año 1977 se publica una reseña en el periódico La Región que da a conocer un pequeño conjunto de monedas de Valencia do Sil que mostrarían, según la reseña, que "nos hallamos ante los restos de un castro romanizado de los siglos III y IV"6. Los ejemplares de monedas reseñadas fue el siguiente:

- Annia Galeria Faustina (Faustina Junior): 145 d.C.

- Lucilla: 161-169 d.C.

- Caius Messius Quintus Traianus Decius (Trajano Decio): 248/251 d.C.

- Publius Licinius Galienus (Galieno): 254/268 d.C.

6 Agradecemos a José Fernández Pérez el acceso a esta noticia. 
- Caius Marcus Cassianus Latinius Postumus (Postumo): 259/268 d.C.

- Marcus Aurelius Numerianus (Numeriano): 282-284 d.C.

- Flavius Valerius Constantinus (Constantino I El Grande): 307/37 d.C.

- Flavius Claudius Iulius Constantinus (Constantino II): 317/337 d.C.

- Flavius Iulius Constante (Constante I): 337/350 d.C.

- Flavius Magnus Magnentius (Magencio): 350/353 d.C.

- Magnus Decentius: 351/353 d.C.

- Magnus Maximo: 383-388 d.C.

En 1983 se publica otra noticia de prensa firmada por Tarsicio González Molina en el Faro de Ourense bajo el título «Tipología de la vivienda en el castro de Valencia del Sil»». En este artículo se especifica que las estructuras exhumadas eran todas de formato rectangular de esquinas redondeadas, de una longitud no mayor de 6 metros de largo. Efectivamente, dos fueron los entornos excavados dentro del yacimiento. El primero, que conocemos un poco mejor gracias a las planimetrías realizadas por el equipo de Os Escarbadores y a los trabajos de limpieza de Santiago Ferrer, se localiza en la zona este del sitio (Figura 4). En este entorno se excavaron hasta ocho habitaciones en dos niveles distintos, todas de formato rectangular y con una significativa organización espacial que podría sugerir la presencia de «barrios» formados por la yuxtaposición de unidades domésticas. Para la construcción de estas estructuras se aterrazó el entorno, rebajando

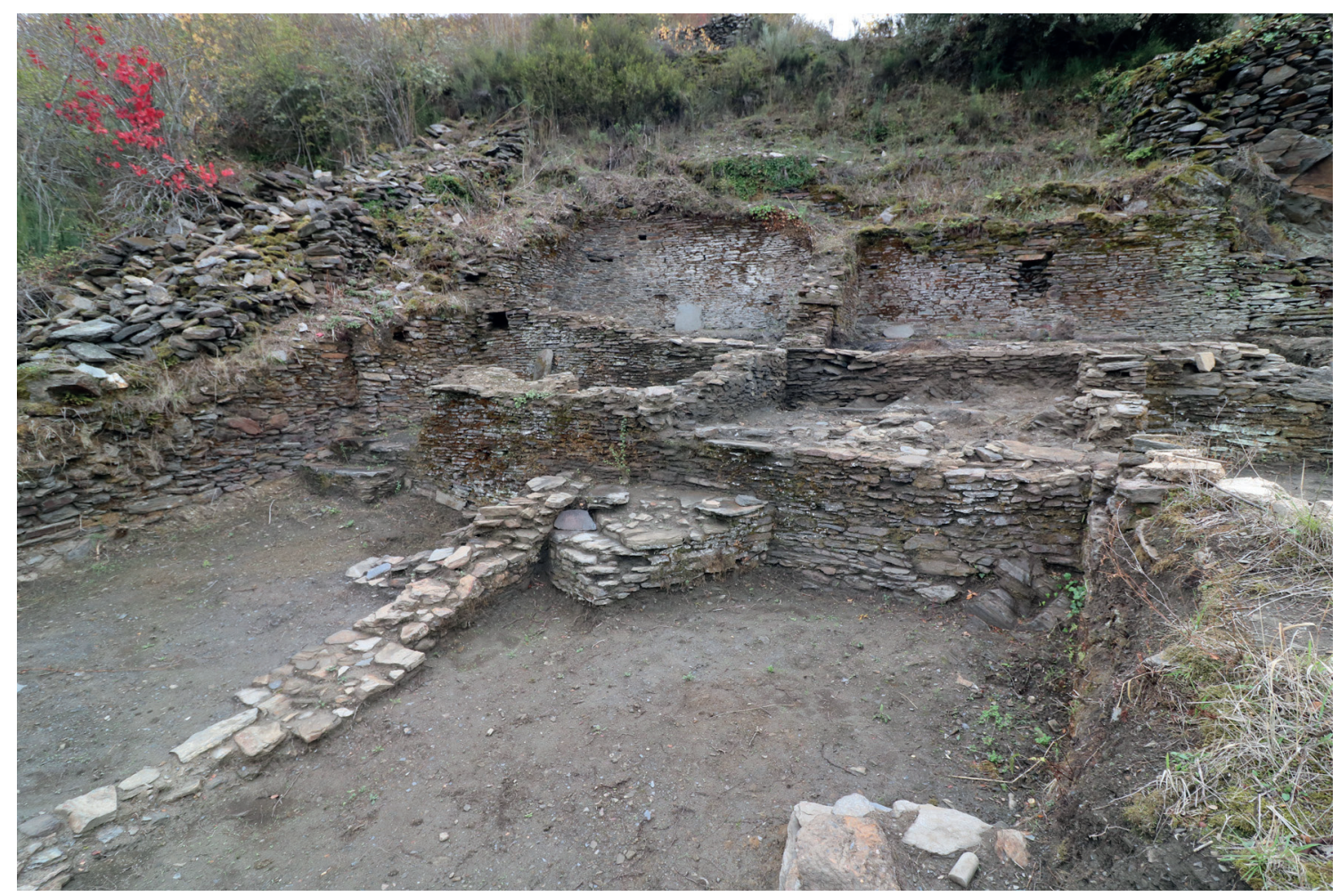

Figura 4. Estructuras del barrio excavado por el grupo Os Escarbadores tras la limpieza realizada por Santiago Ferrer en 2019.

7 Agradecemos a Santiago Ferrer esta referencia. 
la roca natural hasta generar la superficie plana necesaria para su construcción, lo que implica un alto grado de planificación y de gasto de recursos. Todas las construcciones se conservan especialmente bien, levantadas con mampuesto de esquisto y cuarcita local trabadas con argamasa. En dos de las estructuras (las nombradas como $\mathrm{n}^{0} 2 \mathrm{y} \mathrm{n}^{\mathrm{o}} 3$ en la planimetría conservada) se conservan hogares formados por lajas de esquisto. El segundo de los contextos, localizado en la zona occidental del yacimiento es conocida como la «casa romana» por el material de esa época que se localizó en el interior. Es muy significativo el hecho de que en esta estructura, de formato rectangular y más amplia que el resto de construcciones, se localizó estuco pintado -parte del cual se conservaba en el material analizado en el concello de O Barco de Valdeorras-, lo que podría sugerir la presencia de diferencias sociales o funcionales destacadas en Valencia do Sil durante su ocupación.

Por otra parte, un conjunto de huesos recuperados en el contexto de la limpieza del sitio en los años 90 fue analizado por Carlos Fernández, de la Universidad de León, en el contexto de su tesis doctoral (FERNÁNDEZ RODRÍGUEZ 2000). Este pequeño lote de huesos, dado que pertenece a una publicación inédita, será incorporado al análisis posterior de los materiales del sitio en este mismo trabajo ${ }^{8}$.

A pesar de la escasez de información conocida sobre este asentamiento, Valencia do Sil se convirtió en un referente territorial para el estudio del fenómeno de re-ocupación de los asentamientos fortificados en época romana tardía. Entre ellos, destacarían los distintos trabajos de J. López Quiroga (LÓPEZ QUIROGA 2004), con especial mención al estudio dedicado a los castella tutiora de la tradición hidaciana firmado junto con M.R. Lovelle (LÓPEZ QUIROGA y LOVELLE 1999). En este trabajo se refieren al sitio como «Castelo», y reconocen la aparición de Terra Sigillata Hispánica Tardía (LÓPEZ QUIROGA y LOVELLE 1999: 359). Esta referencia se recogerá en la obra de síntesis de Á. Rodriguez Resino (RODRIGUEZ RESINO 2006: 166), así como en el trabajo de J.C. Sánchez Pardo, donde escribe sobre el sitio que: «Este enclave posee un importante dominio del entorno, incluyendo el asentamiento urbano a sus pies, el rio Sil, la vía XVIII y el transporte de metales extraídos de esta rica zona minera. A sus faldas se hallo un capitel de mármol suevo-visigótico, de estilo corintio que según Rodríguez Colmenero pertenecería quizá a una sencilla construcción paleocristiana o germánica en el lugar» (SÁNCHEZ PARDO 2012: 35). Efectivamente, en un libro sobre el Priorato de Xagoaza, se describen distintos elementos constructivos localizados en la zona que los autores datan en «época suevo-visigótica», incluyendo varios capiteles (Figura 5), una pilastra y un cancel (RODRÍGUEZ COLMENERO, et al. 2009: 79-80). Igualmente, el asentamiento de Valencia do Sil fue uno de los revisados en la reciente publicación sobre este proyecto en el que asociábamos el sitio a una red de asentamientos fortificados ocupados en época tardoimperial y sueva para el control del comercio en el Sil (FERNÁNDEZ PEREIRO, TEJERIZO GARCÍA, RODRÍGUEZ GONZÁLEZ, LIXÓ GÓMEZ, y CARVAJAL CASTRO 2017).

8 Agradecemos a Carlos Fernández las facilidades para acceder a los datos de su Tesis Doctoral. 


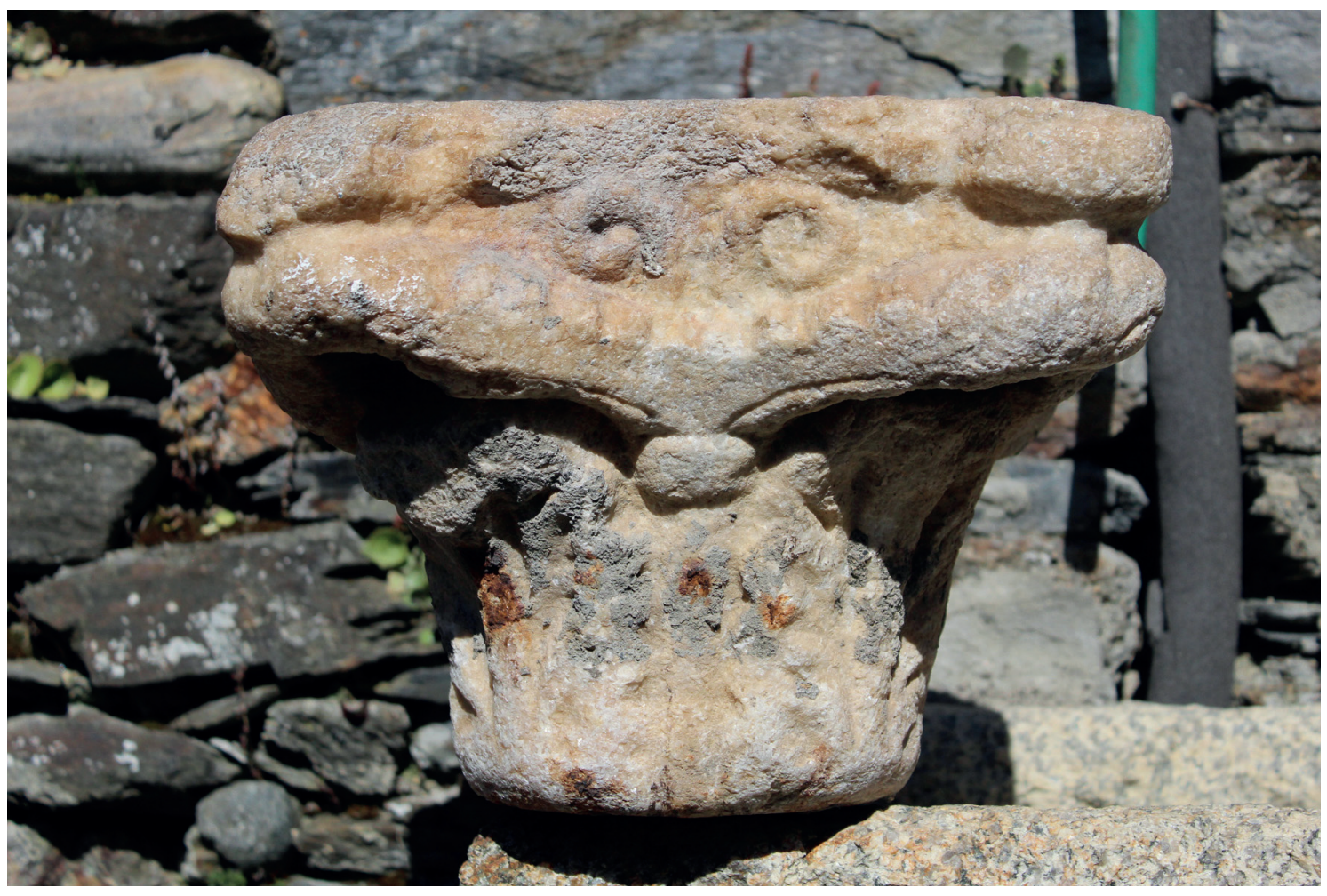

Figura 5. Capitel vinculado al asentamiento de Valencia do Sil. Fotografía de los autores.

\section{AnÁlisis de materiales}

Como ya se comentaba anteriormente, el material analizado se encontraba en los almacenes del ayuntamiento de O Barco de Valdeorras, en distintas bolsas y cajas sin ningún tipo de indicación más que una numeración correlativa en las bolsas. Por lo tanto, aunque los números correlativos de las bolsas nos indicaban que procedían del mismo entorno arqueológico, no contamos con un contexto estratigráfico definido para los materiales. Algunas de ella contenían tarjetas en las que se indicaba la procedencia del material de algunas de las habitaciones excavadas en el contexto nororiental del sitio, lo que nos permite vincular sin duda este material con ese espacio. Por lo tanto, lo más probable es que la mayoría del material proceda de las estratigrafías asociadas a estas estructuras y, por lo tanto, de los estratos de uso y abandono de las mismas. Sin embargo, esto es una hipótesis que deberá ser corroborada en futuras excavaciones para saber si el material estratigráfico coincide con el analizado.

Pasamos a continuación a analizar el material de Valencia do Sil en función a su tipología, prestando especial atención, por su cantidad y relevancia, al material cerámico.

\subsection{El material cerámico}

Hasta hace relativamente poco el análisis de la cerámica de época tardorromana y sueva -así como de la cerámica altomedieval en general- estaba muy poco desarrollado. Apenas se conocían contextos que pudieran ser datados con un cierto grado de segu- 
ridad entre los siglos V y VIII d.n.e., lo que generaba que la cronología de muchos yacimientos fuera desconocida o se hubiera establecido erróneamente. Sin embargo, en la última década y media, gracias a la excavación y análisis de numerosos contextos de este período, el repertorio cerámico de estos siglos se va conociendo con cierto grado de profundidad (recientes síntesis en MARTÍN VISO, FUENTES MELGAR, SASTRE BLANCO, y CATALÁN RAMOS 2018; VIGIL-ESCALERA y QUIRÓS CASTILLO 2016). En el caso del noroeste peninsular, si bien a un ritmo distinto, ya existen algunos análisis cerámicos de referencia que nos permiten afrontar con un nivel mayor de detalle conjuntos cerámicos como el de Valencia do Sil, tanto en sus aspectos cronológicos como en los tecnológico-productivos (ALCORTA IRASTORZA y BARTOLOMÉ ABRAIRA 2012; FERNÁNDEZ FERNÁNDEZ y BARTOLOMÉ ABRAIRA 2016; PAZ PERALTA 2013; TEJERIZO GARCÍA, RODRÍGUEZ GONZÁLEZ, y FERNÁNDEZ PEREIRO 2018, 2019).

Siguiendo estos estudios, el análisis realizado partió de un reconocimiento y diferenciación macroscópica de cada una de las producciones presentes en el conjunto. Así, el objetivo era distinguir las diferentes Cadenas Tecnológico-Operativas, esto es, los diferentes procesos completos, la serie de gestos y técnicas que llevan una materia, en este caso la arcilla, hasta su estado final, la cerámica, prestando atención a cada uno de los elementos constitutivos de la misma y que aporten información relevante sobre estos procesos (LEMONNIER 1986; VAN DER LEEUW 1977). De esta manera, características como el color de la pasta, el tipo de desgrasantes utilizados, las formas para formar el cacharro cerámico (torno rápido, torno lento, movimientos manuales...) o el tipo de cocción recibida son algunos de los elementos que, a nivel macroscópico, nos permiten distinguir estas cadenas. Una vez diferenciadas las producciones, estas eran cuantificadas siguiendo el sistema de doble registro proveniente del ámbito anglosajón: el número de fragmentos y el peso en gramos. Esta cuantificación permite analizar la importancia de una producción dentro del conjunto total, aspecto esencial para determinar, por ejemplo, la datación de los conjuntos en el período que aquí nos ocupa (ADROHER AUROUX, et al. 2016; VIGIL-ESCALERA 2006). Esta metodología ha sido ya utilizada en el análisis de otros contextos muy similares a Valencia do Sil con éxito, como en el caso de los cercanos yacimientos de Castro Ventosa o Viladonga (TEJERIZO GARCÍA 2016b; TEJERIZO GARCÍA, et al. 2018; TEJERIZO GARCÍA y VIGIL-ESCALERA GUIRADO 2017; VIGIL-ESCALERA 2003).

Partiendo de esta metodología, se pudieron cuantificar un total de 4663 fragmentos con un peso total de 70,2 kg. El Número Mínimo de Individuos (NMI) presentes en el conjunto no ha podido ser calculado, dada la falta de contextos estratigráficos asociados que permitan una unidad coherente de análisis de esta variable (ADROHER AUROUX, et al. 2016). Como indica el Índice de Fragmentación calculado (cercano al o,15), el conjunto está muy fragmentado, dando lugar a muy pocos perfiles completos. Las producciones diferenciadas y su cuantificación se resumen en la tabla siguiente: 
Tabla 1. Cuantificación de las producciones documentadas en Valencia do Sil.

\begin{tabular}{|c|c|c|c|c|c|c|}
\hline PRODUCCIÓN & DESCRIPCIÓN & FRAG. & $\%$ FRAG & PESO & $\%$ PESO & IF $^{9}$ \\
\hline TS & Terra sigillata genérica o indeterminada & 17 & 0,4 & 37 & 0,1 & 0,45 \\
\hline TSHTLisa & Terra sigillata Hispánica Tardía sin decoración & 170 & 3,6 & 549 & 0,8 & 0,3 \\
\hline TSHTDecor & Terra sigillata Hispánica Tardía decorada & 3 & 0,1 & 21 & 0,02 & 0,14 \\
\hline TSEstamp & $\begin{array}{l}\text { Terra sigillata Hispánica Tardía con decoración } \\
\text { estampillada }\end{array}$ & 1 & 0,02 & 2 & 0,002 & 0,5 \\
\hline CIS & $\begin{array}{l}\text { Cerámica Imitación de Sigillata (CIS). Normalmente } \\
\text { con presencia de barnices color ocre y avellanas con } \\
\text { desgrasantes de pequeño y mediano tamaño de } \\
\text { cuarzo y mica plateada. }\end{array}$ & 19 & 0,4 & 183 & 0,3 & 0,1 \\
\hline CCRA & $\begin{array}{l}\text { Cerámica a torno rápido y cocción oxidante con } \\
\text { pastas bien depuradas con desgrasantes de mediano } \\
\text { tamaño de cuarzo. }\end{array}$ & 86 & 1,8 & 1287 & 1,8 & 0,06 \\
\hline CCRB & $\begin{array}{l}\text { Cerámica a torno rápido y cocciones mixtas } \\
\text { (tendente a oxidantes) de pastas poco depuradas con } \\
\text { desgrrasantes de mediano y gran tamaño de cuarzo, } \\
\text { mica, mica plateada y chamota. }\end{array}$ & 2339 & 50,2 & 36163 & 51,5 & 0,06 \\
\hline CCRC & $\begin{array}{l}\text { Cerámica a torno rápido y cocciones oxidantes o } \\
\text { mixtas de pastas semidepuradas con desgrasantes de } \\
\text { mediano tamaño de cuarzo y mica. }\end{array}$ & 36 & 0,8 & 551 & 0,8 & 0,06 \\
\hline Dolia & $\begin{array}{l}\text { Cerámica de características muy similares a la CCRB } \\
\text { pero asociadas a formas de grandes contenedores, } \\
\text { caracterizadas por los grandes tamaños y paredes } \\
\text { muy ǵruesas en pastas de cocción mixta normalmente } \\
\text { poco depuradas. }\end{array}$ & 44 & 0,9 & 6589 & 9,4 & 0,006 \\
\hline Engobada & $\begin{array}{l}\text { Producciones a torno rápido de cocciones mixtas, } \\
\text { normalmente oxidante al exterior y reductora al } \\
\text { interior. Presencia de abundantes desgrasantes de } \\
\text { mica plateada de mediano y ǵran tamaño. }\end{array}$ & 720 & 15,4 & 8027 & 11,4 & 0,08 \\
\hline $\begin{array}{l}\text { Imitación de Paredes } \\
\text { finas }\end{array}$ & $\begin{array}{l}\text { Producciones a torno de pastas blancas } \\
\text { semidepuradas o depuradas con desgrasantes dde } \\
\text { pequeño tamaño de cuarzo, mica plateada y chamota } \\
\text { con grosores muy pequeños ( }<5 \mathrm{~mm}) \text {. Algunas } \\
\text { aparecen pintadas con motivos en ocre (ondas } \\
\text { normalmente) e incisiones. }\end{array}$ & 71 & 1,5 & 333 & 0,5 & 0,21 \\
\hline Ánfora & $\begin{array}{l}\text { Cerámica de características muy similares a la CCRB } \\
\text { pero asociadas a formas de ánfora, caracterizadas por } \\
\text { los grandes tamaños y paredes muy gruesas en pastas } \\
\text { de cocción oxidante muy poco depuradas. }\end{array}$ & 17 & 0,4 & 975 & 1,4 & 0,02 \\
\hline TRA & $\begin{array}{l}\text { Cerámica a torno rápido y cocción reductora, bien } \\
\text { depurada con desograsantes medianos y pequeños de } \\
\text { cuarzo y mica plateada de buena calidad. }\end{array}$ & 27 & 0,6 & 124 & 0,2 & 0,21 \\
\hline TRB & $\begin{array}{l}\text { Cerámica a torno rápido y cocción reductora, } \\
\text { escasamente depurada con desgrasantes de mediano } \\
\text { y gran tamaño }(>5 \mathrm{~mm} \text {.) de chamota, cuarzo y mica } \\
\text { plateada y dorada. }\end{array}$ & 743 & 15,9 & 12542 & 17,8 & 0,05 \\
\hline TRC & $\begin{array}{l}\text { Cerámica a torno rápido, semidepuradas y con } \\
\text { desgrasantes de mediano tamaño de cuarzo y mica } \\
\text { plateada. Variante de pastas muy jabonosas. }\end{array}$ & 367 & 7,9 & 2715 & 3,9 & 0,13 \\
\hline Indet & Producciones indeterminadas & 3 & 0,1 & 189 & 0,3 & 0,01 \\
\hline
\end{tabular}

9 Este índice se ha obtenido a partir de la división entre fragmentos de una CTO y su peso, y que sería un indicativo del tamaño medio de los fragmentos analizados por cada CTO. Así, un número muy bajo indicaría un gran peso por cada uno de los frağmentos y, por lo tanto, un tamaño medio superior de los mismos asociado a una menor fragmentación. Igualmente, se puede analizar como un indicativo de la representatividad de las CTOs dentro del conjunto. 
Lo primero que llama poderosamente la atención es que, a pesar de la significativa cantidad de material analizado no se han documentado ni conjuntos ni fragmentos claramente adscribibles a un momento prerromano. Este tipo de producciones son fácilmente diferenciables no sólo por su característica cocción reductora o por los motivos decorativos utilizados -estampillados y bruñidos principalmente-, sino también por la factura a mano que deja unas superficies irregulares muy reconocibles (FERNÁNDEZ FERNÁNDEZ 2008; GONZÁLEZ-RUIBAL 2006-2007; MARÍN SUÁREZ 2012; REY CASTIÑEIRA 2010). Otros contextos similares analizados, como el caso de Viladonga, presentaban una importante cantidad de materiales de época castrexa, cercanas a la mitad del material analizado - un total de 5751 fragmentos y 110,7 kg. de peso en aquel caso- que visibilizaban la ocupación del sitio durante este período (ARIAS VILAS, DURÁN FUENTES, BASTOS BERNÁRDEZ, y VARELA ARIAS 2013; DORREGO MARTÍNEZ y RUBIERO DA PENA 1998; TEJERIZO GARCÍA, et al. 2018). Su ausencia en todo el material revisado de Valencia do Sil indicaría que, a la espera de una excavación estratigráfica que corrobore esta hipótesis, el sitio no fue ocupado durante este período ${ }^{10}$. Esto marcaría una cronología de ocupación post quem, al menos, del s.II d.n.e., dado que este es el momento en el que este material de tradición castrexa deja de aparecer definitivamente en los conjuntos (GONZÁLEZ-RUIBAL 2006-2007). Esto no descarta que, como veremos más adelante, la primera ocupación del sitio se produjese, probablemente, en un momento posterior.

Figura 6. Cerámica vinculada a

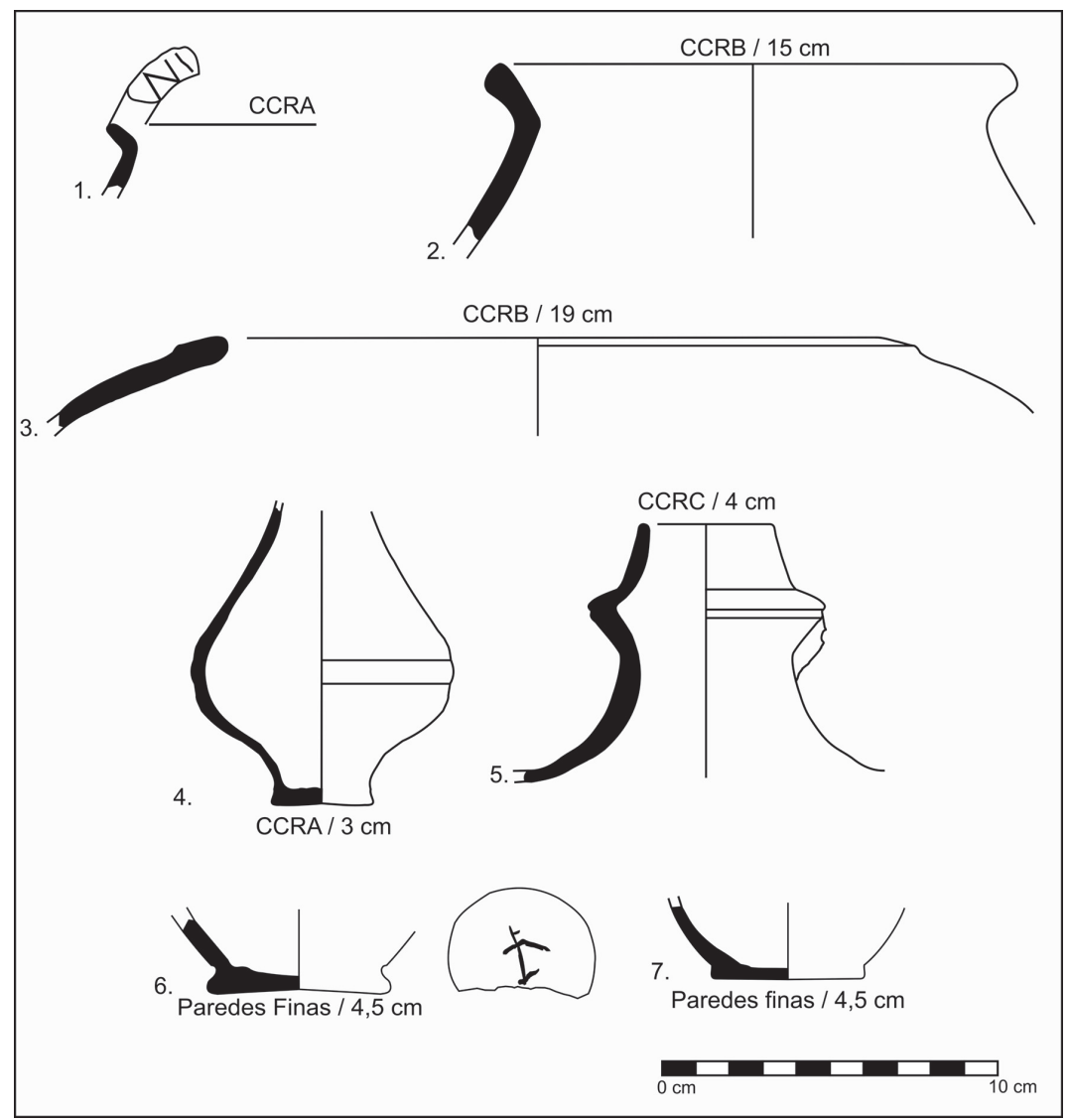
bujos de A. Scaro.

10 Esta afirmación se refiere sobre todo a los espacios domésticos excavados, lo que no descarta que exista una ocupación prehistórica en la parte más alta del asentamiento, como nos ha sugerido Santiago Ferrer, a quien agradecemos toda la información y sugerencias aportadas a esta investigación. 
Como puede comprobarse, el grueso del material cerámico corresponde a la producción denominada como CCRB (50,16\% de los fragmentos y 51,45\% del peso), correspondiente a producciones oxidantes poco depuradas vinculadas tradicionalmente a los llamados ciclos de la "cerámica común romana" (Figura 6). Prácticamente todas las formas reconocidas de esta producción corresponden a formas cerradas tipo ollas, destinadas a la cocina de alimentos. De hecho, en muchas de ellas se conservan restos de exposición al fuego. Entre estas, se han podido distinguir algunas formas de ollas de pequeño tamaño con el borde vuelto y labio redondeado así como algunos ejemplares de ollas con borde vuelto hacia adentro, variantes tardías del tipo 3 de Vegas (Figura 6.3; VEGAS 1973: 18). Como una subvariante de este grupo se documentarían los grandes recipientes de almacenaje o dolia, que correspondería a un 0,94\% de los fragmentos y a un 9,37\% del peso total. Lamentablemente no se conservó en el conjunto analizado ningún borde que pudiera dar una idea de las formas y tamaños específicos de estos contenedores, si bien en general muestran pequeños volúmenes, característico de los conjuntos más tardíos en los que se localizan, ya en la cuarta (TEJERIZO GARCÍA 2016a).

Junto a éstas, se documentó un pequeño conjunto de cerámicas caracterizadas por su cocción oxidante y pastas semidepuradas de color anaranjado y/o ocre (tipos CCRA y CCRC; 2,61\% de peso). Las formas asociadas a esta producción corresponden en su mayoría a pequeños contenedores de líquido, tipo jarras o similares. De las pocas formas reconocidas destaca una jarra de cuello moldurado y engrosado de dos asas (Figura 6.5), así como un pequeño vasito de fondo resaltado y estrecho con cuerpo globular (Figura 6.4). Formas muy similares son reconocidas en otro tipo de producciones, como las producciones con engobe procedentes de Lugo y de una cronología muy amplia que abarcaría desde el siglo I hasta el V d.n.e. (tipo V2b, con asa) (ALCORTA IRASTORZA y BARTOLOMÉ ABRAIRA 2012). Muy similares a la localizada en Valencia do Sil serían los ejemplares de Viladonga, datados a partir de la segunda mitad del siglo IV d.n.e. (TEJERIZO GARCÍA, et al. 2018).

Como una variante de estas formas más depuradas, se encontrarían algunos fragmentos que, por sus características, podrían recordar a las producciones conocidas como "paredes finas", con una alta depuración que deja unas paredes extremadamente finas, con cocciones oxidantes y pastas blanquecinas (1,52\% de los fragmentos y 0,47\% del peso), a las que seguramente imitan, como se ha propuesto para las producciones coetáneas en la ciudad de Braga (FERNÁNDEZ FERNÁNDEZ y BARTOLOMÉ ABRAIRA 2016). En ocasiones este tipo de producciones recibe una decoración pintada, por lo que se han venido denominando "cerámicas pintadas de tradición indígena", por su parecido con algunas producciones características de la Segunda Edad de Hierro de la meseta norte (ABASCAL PALAZÓN 1986). Estas cerámicas se producen de forma muy masiva en los primeros siglos de dominación romana, pero su uso, a través de distintas imitaciones, se prolonga hasta la quinta centuria (BUSTAMANTE ÁLVAREZ 2016).

Muy interesante es la aparición de algunos fragmentos de ánforas dentro del conjunto como una producción muy particular. Esta producción representa, sin embargo, una minoría dentro del conjunto, equivalente al o,36\% de los fragmentos y al 1,39\% de peso ${ }^{11}$. Única-

11 No se descarta, sin embargó, que algunnos fraǵmentos de galbo clasificados como CCRB pertenezcan a ánforas. 
mente son dos los perfiles de ánforas conservados, incluido uno muy posiblemente derivado de una forma tardía de Dressel 28 (Figura 7). Ambas pertenecerían a la categoría de ánforas de "fondo plano" y que tienen una amplia distribución a partir del s. I d.n.e. (MORAIS, MORILLO CERDÁN, DJAOUI, y PEREIRA 2015). Estas producciones, a pesar de su origen bético, desarrollaron variantes locales en el noroeste peninsular y "usados no transporte e armazenamento de produtos, a longa, média e curta distância” (MORAIS, et al. 2015: 51). Este tipo de ánforas de fondo plano se han localizado en numerosos contextos del noroeste peninsular de cronologías tardorromanas, que incluyen yacimientos como Viladonga, Armeá, Lugo o Braga (FERNÁNDEZ FERNÁNDEZ 2014; MORAIS, et al. 2015).

Figura 7. Formas de ánfora documentadas en el material analizado. Dibujos de A. Scaro.

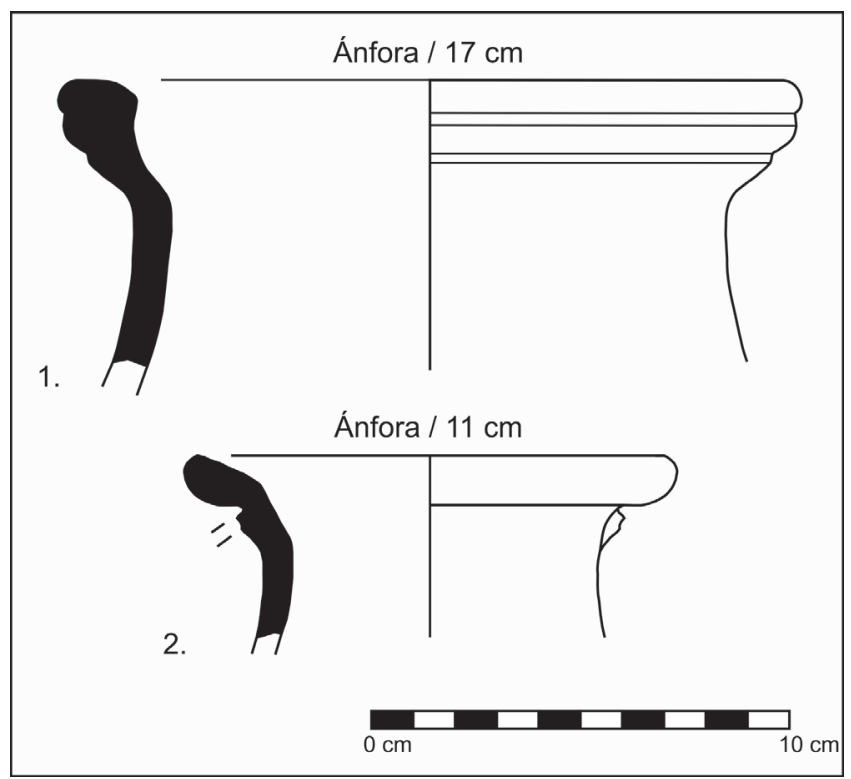

El número de sigillatas reconocidas en el conjunto es muy pequeño, inferior al $1 \%$ de los fragmentos y menos del 0,9\% del peso ${ }^{12}$. Dentro de ellas se han podido documentar, sobre todo, formas de sigillata tardía (TSHT). Únicamente tres fragmentos de TSHT tienen decoración, reducida a motivos muy fragmentarios de círculos concéntricos y flechas correspondientes al "segundo estilo" de Mayet o grupo 2A/B de Vigil-Escalera (VIGILESCALERA 2015: 290-291 y 294-297) y datado entre finales del s.IV d.n.e. y mediados del s. V d.n.e. Muy interesante es la aparición de un fragmento de sigillata estampillada con motivo de palmeta, dentro del grupo 4B de Vigil-Escalera y que se encuadran dentro de la primera mitad de la quinta centuria (VIGIL-ESCALERA 2015: 299-300). Por último, mencionar un pequeño conjunto de cerámicas de imitación de sigillata (CIS; 0,41\% de los fragmentos y 0,26\% del peso) caracterizados por los acabados de color avellana y que marcarían una cronología entre mediados del s. V y mediados del s. VI. Algunas de las formas reconocidas tienen paralelos en distintos yacimientos de la meseta norte y del noroeste, incluido el yacimiento de Viladonga (JUAN TOVAR 2012).

12 El ínfimo número de sigillatas encontrado podría relacionarse al conjunto de materiales que se llevaron del yacimiento durante los años 90 y 2000. Cabe pensar que se llevaron el material más significativo, que incluirían las sigillatasy, sobre todo, sus formas decoradas. 


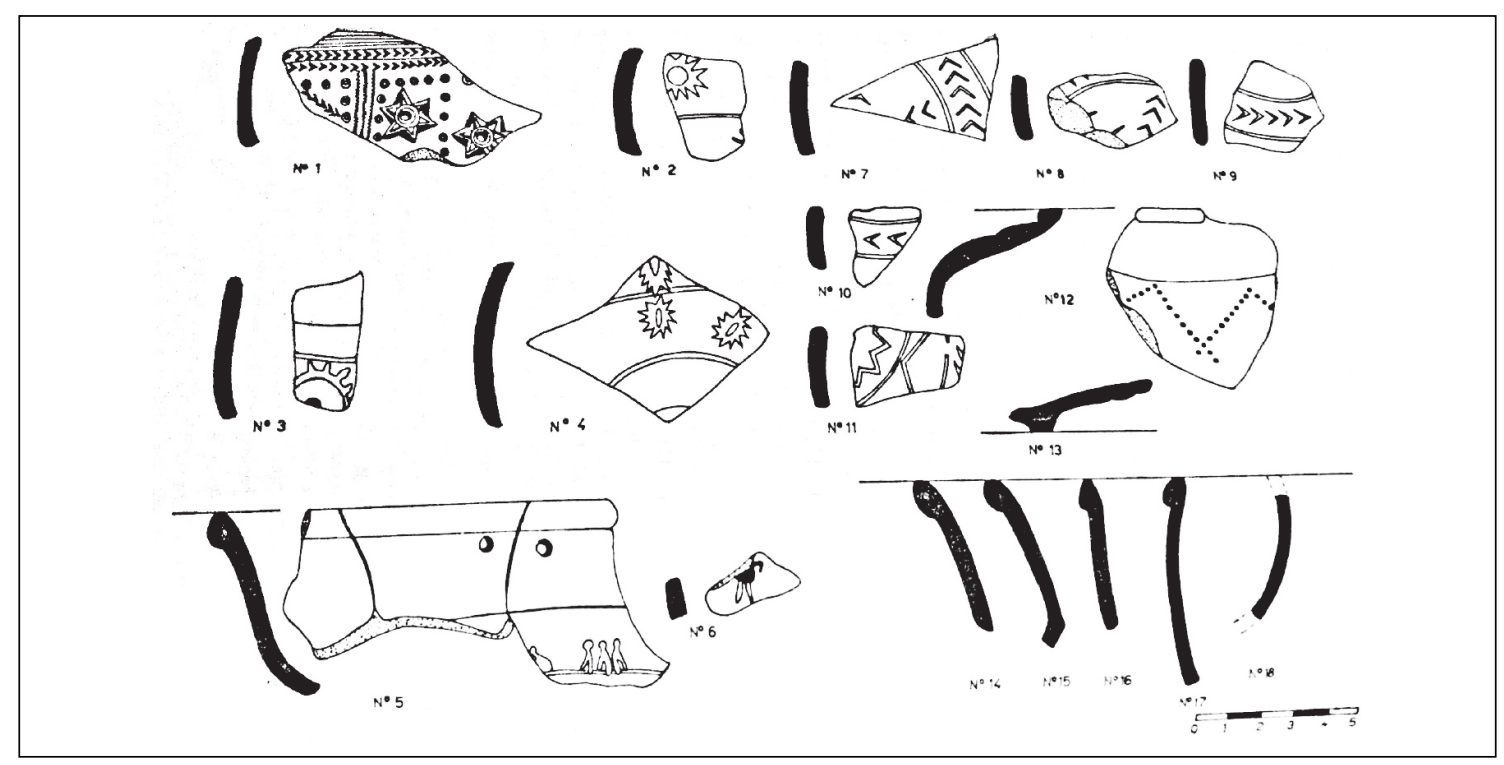

Figura 8. Sigillatas documentadas en Valencia do Sil (Méndez Revuelta, 1974-1975).

Es necesario hacer mención aquí de los 18 fragmentos analizados por C. Méndez (MÉNDEZ REVUELTA 1974-1975), cuya ubicación actual es desconocida (Figura 8). De este estudio cabe destacar que la mayoría de los fragmentos corresponden a formas tardías del cuenco 37 así como a vasos con forma Ritterling 8, ambos encuadrables entre el siglo IV y mediados del s. $\mathrm{V}$ d.n.e. Formalmente destaca la pieza $\mathrm{n}^{\mathrm{0}} 12$, descrita como un "vaso globular" con "decoración punteada formando una serie de "dientes de lobo" o líneas en zig-zag" (MÉNDEZ REVUELTA 1974-1975: 302). Esta forma correspondería a una variante de la forma 42 dentro de las sigillatas tardías, caracterizada precisamente por la tendencia a cerrarse en la parte superior con borde vertical o inclinado para adentro, a veces almendrado (PAZ PERALTA 1991: 155-160) y que tendría una perduración muy larga en el tiempo, desde el siglo II d.n.e. hasta la desaparición de la sigillata a mediados de la quinta centuria (ROCA ROUMENS y FERNÁNDEZ GARCÍA 1999). Se trataría, igualmente, de una forma muy similar a la forma 23 de Rigoir, si bien con la diferencia de que esta última se situaría ya dentro de las producciones grises características de los siglos V y VI d.n.e. (RIGOIR 1968).

Por su parte, las decoraciones de este conjunto corresponden a las típicas de los momentos tardíos de la producción de sigillata, como son los grandes círculos con aspas (fragmentos 7-10), motivos dentados (fragmentos 3) o vegetales (fragmentos 2 y 4). Igualmente cabe destacar la posible presencia de posibles figuras antropomorfas (fragmentos 5 y 6). Llama la atención la presencia en el conjunto del fragmento $n^{0} 1$. Se trata de una forma de Drag. 37 con decoración metopada separadas por líneas onduladas y líneas de puntas de flecha que "enmarcan sendas rosetas de seis pétalos" y que la autora dataría en el siglo II d.n.e. (MÉNDEZ REVUELTA 1974-1975: 300). La presencia de este fragmento, único en todo el conjunto, marcaría una diferencia sustancial con respecto al resto de material por las tempranas cronologías que marca, llamando la atención sobre la potencial presencia de una ocupación anterior al grueso de las producciones documentadas. Sin embargo, la ausencia de datos sobre su proveniencia y de un contexto estratigráfico definido así como su rareza dentro de todo el conjunto analizado lleva a la 
precaución -como con el resto de materiales aquí presentados- hasta tener contextos estratigráficos que permitan datar con rigurosidad la ocupación del yacimiento.

Otra producción muy presente en el conjunto analizado de Valencia do Sil son las producciones engobadas, caracterizadas por las cocciones oxidantes y la aplicación, en distintas partes del cacharro, de una pequeña película de barro líquido para impermeabilizar la cerámica (Figura 9). Estas producciones están estrechamente relacionadas con la ciudad de Lugo, donde fueron producidas de forma masiva ya desde el siglo I d.n.e. hasta, al menos, la quinta centuria, y con una distribución que parece alcanzar amplias zonas no sólo del noroeste peninsular sino también de la meseta norte (ALCORTA IRASTORZA 2001). En Valencia do Sil, se ha documentado un amplio conjunto de esta producción que alcanza al 15,44\% de los fragmentos y el 11,42\% del peso. Como muestran los estudios de E.J. Alcorta y otros autores, bajo esta producción se fabrican cerámicas de formas muy variadas, tanto abiertas como cerradas. En el caso de Valencia do Sil, se han documentado, sobre todo, formas de jarras, platos y barreños. Más específicamente, se pudieron identificar varias formas de barreños o platos tipo EP2 (Figura 9.1; 9.2; 9.3; 9.4), con el borde ligeramente vuelto y engrosado. Este tipo de producciones, si bien arrancan ya desde el siglo I/II d.n.e., permanecen en el repertorio cerámico de Lugo hasta época tardoimperial (ALCORTA IRASTORZA y BARTOLOMÉ ABRAIRA 2012: 718). También está presente la forma 18T, un cuenco de cronología tardoimperial (ALCORTA IRASTORZA y BARTOLOMÉ ABRAIRA 2012: 719), con una decoración de líneas incisas en el borde (Figura 9.13). Finalmente se han documentado varias formas de ollas de borde vuelto y formato globular de diversos tamaños.

Cuantitativamente similar a las producciones engobadas se encuentran aquellas caracterizadas por las cocciones reductoras realizadas a torno rápido y de pastas poco depuradas, que denominamos TRB (15,93\% de los fragmentos y 17,84\% del peso) (Figura 10). Este tipo de producciones, si bien comienzan a aparecer en el registro arqueológico ya en época romana tardoimperial vinculada a algunas variantes de la cerámica común, no se hace significativa en los conjuntos cerámicos hasta la segunda mitad del siglo IV d.n.e., siendo predominante ya desde el siglo VI d.n.e. (FERNÁNDEZ FERNÁNDEZ y BARTOLOMÉ ABRAIRA 2016; TEJERIZO GARCÍA 2016a). En el conjunto de Valencia do Sil se pudieron documentar varias formas de ollas globulares de borde vuelto y engrosado así como algunas formas de jarra para contener líquidos con molduras en el cuello, muy características desde la segunda mitad del siglo $\mathrm{V}$ d.n.e. y que podrían llegar hasta el siglo VII d.n.e. (TEJERIZO GARCÍA 2016a). Sin embargo, la ausencia de una significativa cantidad de materiales realizados a torno lento, característico de los conjuntos cerámicos de la séptima centuria, invitarían a pensar en un terminus ante quem de ocupación del sitio a mediados del siglo VI d.n.e. (VIGIL-ESCALERA 2003; VIGIL-ESCALERA y QUIRÓS CASTILLO 2016). Por otro lado, algunas formas de plato o barreño en producciones grises recuerdan a las mismas formas pero en producciones engobadas, cuya cronología antecede a estas de cocciones reductoras. Esto podría sugerir que estas producciones reductoras vendrían a sustituir a sus formas homólogas en otro tipo de producciones, como la engobada, cuestión que ya ha sido sugerida en otras publicaciones (FERNÁNDEZ FERNÁNDEZ y BARTOLOMÉ ABRAIRA 2016). 


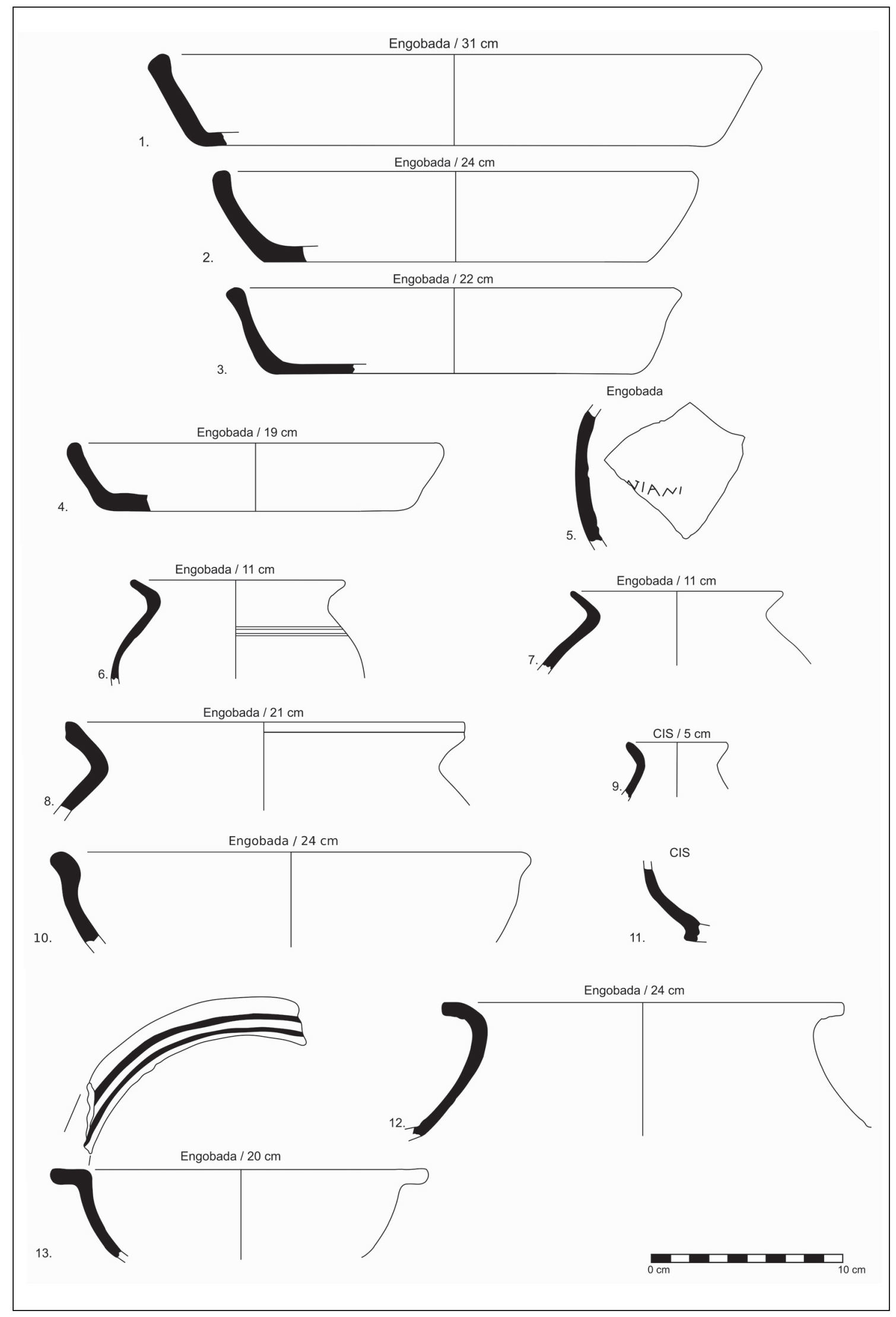

Figura 9. Producciones engobadas localizadas en Valencia do Sil. Dibujos de A. Scaro. 


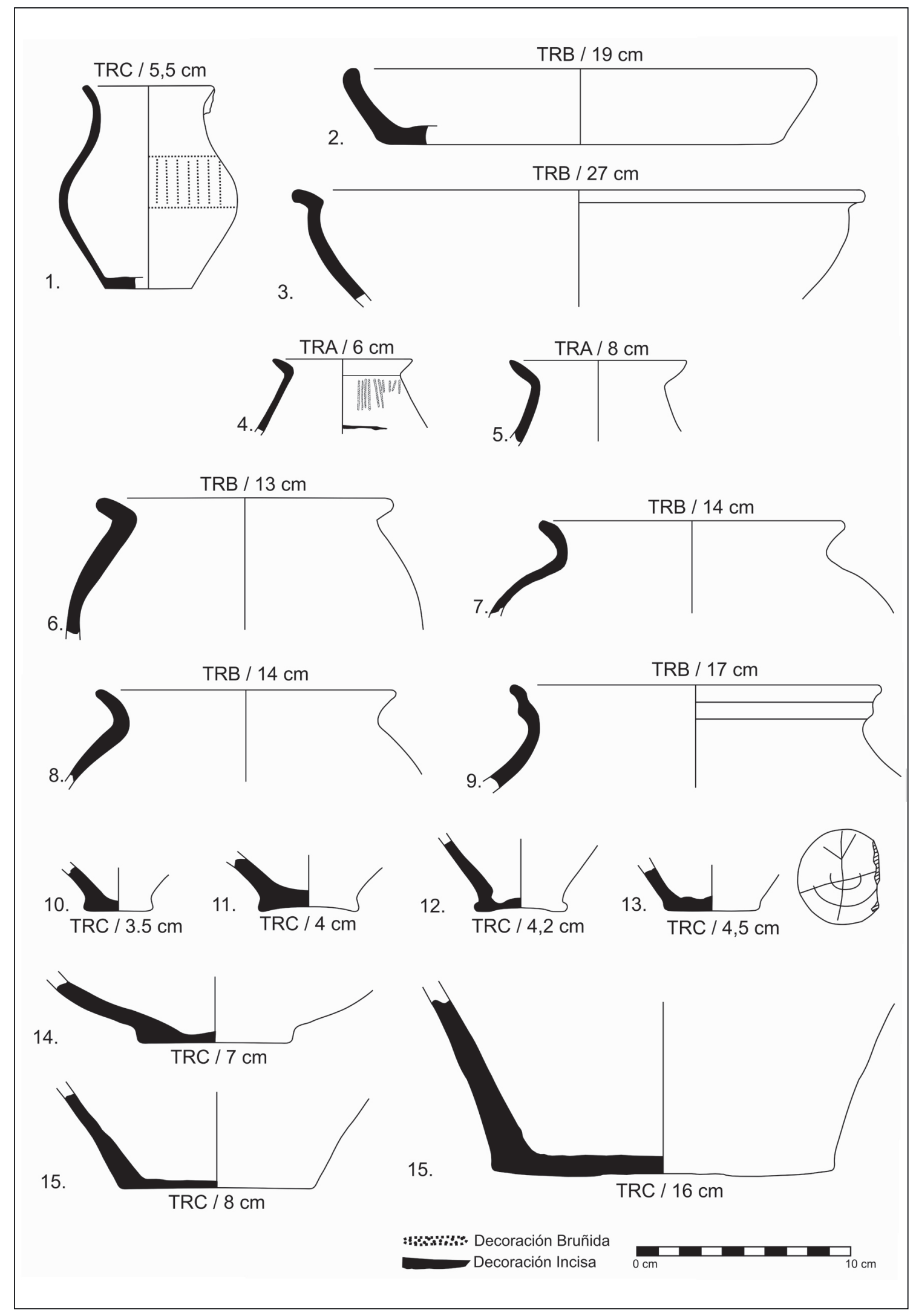

Figura 10. Producciones con pastas grises localizadas en Valencia do Sil. Dibujos de A. Scaro. 
Dentro de estas producciones de cocción reductora se ha distinguido un pequeño grupo con una mayor depuración (TRC y TRA; 8,4\% de los fragmentos y 4\% del peso) y asociada a producciones destinadas a contener líquidos como jarras o pequeños vasos. Entre estos destaca la presencia de jarras de pequeño tamaño $(6-8 \mathrm{~cm}$. de boca) de labio exvasado y borde recto que generan una pequeña cuenca para la recepción de una tapadera (Figura 10.6-9). Del mismo modo destaca la aparición de un pequeño vaso globular con decoración en líneas verticales bruñidas muy similar al ya descrito anteriormente y con paralelos en el yacimiento de Viladonga (Figura 13.1; TEJERIZO GARCÍA, et al. 2018). Por último, se documentaron un conjunto de fondos anulares resaltados que, en este tipo de producciones, son muy típicos de los siglos V y VI d.n.e. en una gran diversidad de yacimientos del norte peninsular (Figura 10.10-14; TEJERIZO GARCÍA 2016a; VIGIL-ESCALERA 2013). Algunos de estos fondos, además, están grafitados con motivos de líneas incisas cruzadas, tipo de decoración también muy habitual de estos momentos, como se muestra en el material de otros yacimientos como Viladonga o Castros de Mondoñedo (Figura 10.13; TEJERIZO GARCÍA, et al. 2018; VIGO GARCÍA 2017).

El repertorio de decoraciones del material cerámico de Valencia do Sil no es especialmente diverso, aunque muy significativo. Entre estas, abundan las decoraciones que utilizan el bruñido, ya sea en forma de líneas verticales o formando retículas (Figura 11). El otro motivo decorativo más común es la incisión, normalmente a través de líneas horizontales u oblicuas, aunque también se ha documentado en líneas cruzadas. En ocasiones, este bruñido se combina con las incisiones, generando retículas muy uniformes que forman rombos a lo largo del cuerpo de la cerámica. Este tipo de decoración bruñida se localiza tanto en las producciones reductoras tipo TRB o TRC como en aquellas engobadas. También se han documentado otros tipos de decoración, como digitaciones (por ejemplo, en barreños engobados y, más comúnmente, en dolias), molduras, estampillados (localizados únicamente en el fragmento de TSHT ya mencionado) o, de forma excepcional, líneas horizontales o serpenteantes pintadas en colores ocre. Todo este repertorio de decoraciones es muy común en los conjuntos cerámicos, sobre todo, de la quinta y sexta centurias en todo del norte y noroeste peninsular (TEJERIZO GARCÍA 2016a; VIGIL-ESCALERA 2006). Sin embargo, llama la atención la ausencia de decoraciones

Figura 11. Decoraciones sobre producciones grises. Fotografía de los autores.

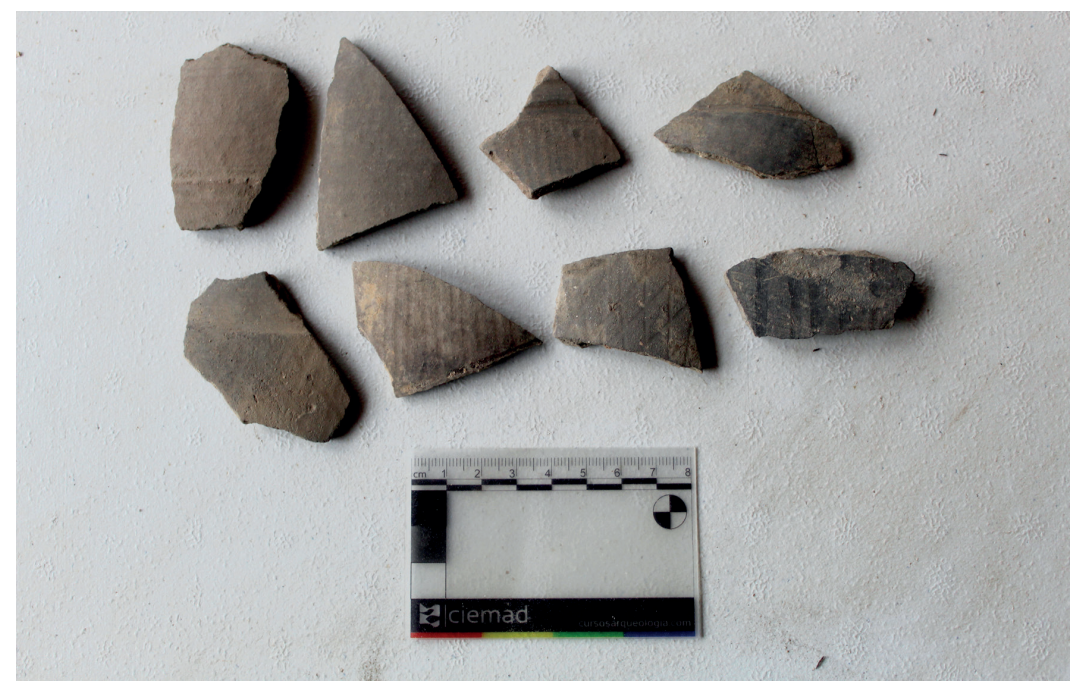


estampilladas, tan comunes de estos momentos en otros entornos del centro peninsular. Esta ausencia de estampillados en beneficio de los bruñidos e incisiones es algo característico del noroeste peninsular, que marcaría una serie de producciones regionales vinculadas a las ciudades de Lugo y de Braga, principalmente, como ya ha sido reconocido por otros autores (FERNÁNDEZ FERNÁNDEZ y BARTOLOMÉ ABRAIRA 2016).

Una decoración muy significativa documentada en el material cerámico revisado son los grafitos. Ya en el inventario del IEV (ver arriba) se hacía mención a algún fragmento de cerámica “con la firma 'M A M", que indicaba la presencia de esta forma decorativa. En el conjunto analizado se documentó un fragmento sobre una superficie engobada en el que se puede leer "[N]IANI" (Figura 9.5). Igualmente, en un pequeño fragmento de producción oxidante, en la zona del labio, se pueden leer las letras "NI" (Figura 6.1). Ambos grafitos se hicieron después de la cocción de la cerámica (conocidos como grafitos post cocturam) y, por lo tanto, no formaron parte de la propia producción de la cerámica. Debido a su terminación es muy posible que haga referencias a nombres en genitivo, por lo que entrarían dentro de la categoría de "inscripciones nominales" cuya función principal "suele ser la de identificar al propietario de la pieza” (OZCÁRIZ GIL 2010).

Antes de finalizar el apartado de las cerámicas hay que hacer mención a un pequeño conjunto de 31 piezas depositadas en el Museo de Ourense asociadas al yacimiento de Valencia do Sil. Su descripción se detalla en la tabla siguiente:

TABLA 2. Cerámicas del yacimiento de Valencia do Sil revisadas en el Museo Provincial de Ourense.

\begin{tabular}{|c|c|l|}
\hline SIGLA & PESO & \multicolumn{1}{c|}{ DESCRIPCIÓN } \\
\hline CE006017/13 & 240 & $\begin{array}{l}\text { 14 fragmentos de dos ollas de cocción reductora de pastas semidepuradas de labio } \\
\text { exvasado y vuelto. Decoración de líneas bruñidas horizontales y verticales. }\end{array}$ \\
\hline CE006017/14 & 8 & Fraǵmento de fondo vidriado melado al interior \\
\hline CE006017/14 & 42 & Fragmento de asa de pastas anaranjadas semidepuradas \\
\hline CE006017/14 & 6 & Fragmento de galbo de cocción oxidante y con posibles restos de engobe \\
\hline CE006017/14 & 18 & Fragomento de asa de cocción oxidante, pastas color ocre poco depuradas \\
\hline CE006017/14 & 7 & Fraǵmento de galbo de cocción oxidante de pastas anaranjadas y semidepurada \\
\hline CE006017/14 & 8 & Fragmento de TSHT de posible fondo con engobe perdido \\
\hline CE006017/14 & 5 & $\begin{array}{l}\text { Fraǵmento de Terra Sigillata forma Ritt. 8 de pastas anaranjadas con engobe rojo } \\
\text { brillante }\end{array}$ \\
\hline CE006017/15 & 3 & Fraǵmento vidriado melado al interior con pastas anaranjadas \\
\hline CE006017/15 & 5 & Fragmento de cerámica engobada con cocción mixta y pastas ǵrisáceas \\
\hline CE006017/15 & 14 & 2 fraǵmentos de galbo de cocción oxidante y pastas semidepuradas \\
\hline CE006017/15 & 125 & $\begin{array}{l}\text { 6 fraǵmentos de olla a torno lento, cocción mixta irregular, pastas ocres y pouco } \\
\text { depuradas }\end{array}$ \\
\hline
\end{tabular}

Salvo por las cerámicas vidriadas, este pequeño conjunto es muy coherente con lo ya descrito para el resto del material cerámico. Dos piezas merecen ser reseñadas. La primera es un fragmento de Terra Sigillata Hispánica Tardía (TSHT) correspondiente a un cuenco de tipo Ritt. 8, muy típico de los siglos IV y V d.n.e. (CE 6017/14). La otra pieza de interés es un fragmento de una olla de gran tamaño $(28 \mathrm{~cm}$. de diámetro de boca) realizada a torno rápido en cocción reductora con labio exvasado y engrosado con decoración 
mediante líneas bruñidas verticales y horizontales. Este tipo de ollas remiten a un horizonte cronológico de la segunda mitad del siglo $\mathrm{V}$ y, más probablemente, ya dentro de la sexta centuria, con paralelos en yacimientos conocidos como Castro Ventosa, Viladonga o Astorga (PAZ PERALTA 2013; TEJERIZO GARCÍA, et al. 2018; TEJERIZO GARCÍA y VIGIL-ESCALERA GUIRADO 2017).

\subsection{Restos óseos}

Como ya se mencionaba anteriormente, en el contexto de las limpiezas de los años 90 se localizó un conjunto de huesos que fueron analizados por C. Fernández dentro de su tesis doctoral (FERNÁNDEZ RODRÍGUEZ 2000). En este conjunto, de 120 restos y 881 gr. de peso se diferenciaron seis especies distintas, que incluyen oveja, cabra, vaca, cerdo, caballo y gato. Los datos se recogen en la siguiente tabla:

TABLA 3. Cuantificación de los restos óseos (FERNÁNDEZ RODRíGUEZ 2000).

\begin{tabular}{|l|c|c|c|c|c|}
\hline \multicolumn{1}{|c|}{ TAXÓN } & $\begin{array}{c}\text { NÚMERO DE } \\
\text { RESTOS }\end{array}$ & $\%$ & $\begin{array}{c}\text { NÚMERO MÍNIMO } \\
\text { DE INDIVIDUOS }\end{array}$ & $\mathrm{P}$ & $\%$ \\
\hline Equus caballus & 1 & 2,1 & 1 & 15 & 3,2 \\
\hline Bos Taurus & 21 & 43,7 & 1 & 331 & 70,4 \\
\hline Ovis aries & 2 & & 1 & 17 & \\
\hline Ovis/Capra & 18 & 41,7 & 2 & 93 & 23,4 \\
\hline Sus domesticus & 5 & 10,4 & 3 & 12 & 2,6 \\
\hline Felis Catus & 1 & 2,1 & 1 & 2 & 0,4 \\
\hline Total determinados & 48 & 40,0 & & 470 & 53,3 \\
\hline Indeterminados & 72 & 60 & & 411 & 46,7 \\
\hline TOTAL & 120 & & & 881 & \\
\hline
\end{tabular}

De este estudio caben mencionar varias cuestiones, ya señaladas por C. Fernández (FERNÁNDEZ RODRÍGUEZ 2000) y que sintetizamos aquí para completar el cuadro de conocimiento sobre este sitio. En primer lugar, destaca la predominancia del ganado vacuno y ovicaprino en el conjunto. En segundo lugar, el análisis determinó la presencia de animales que, bien por su propio taxón (como el caballo), bien por su edad adulta (como el único ejemplar de vaca analizado), fueron utilizados principalmente como animales de tiro, previsiblemente en labores de tipo agrícola. En tercer lugar, se observa que el sacrificio en edad adulta de los ovicaprinos, lo que indicaría un aprovechamiento intensivo del animal. Por último, la ausencia de animales salvajes provenientes de actividades de caza, si bien esto podría ser resultado del reducido tamaño de la muestra.

A pesar de lo pequeño del conjunto, este responde a los principales parámetros de aprovechamiento animal en época romana y postromana, caracterizado por una significativa presencia de los vacunos y de los ovicaprinos sobre, por ejemplo, los suidos (GRAU SOLOGESTOA 2015). Características estas que han sido reconocidas en otros pequeños conjuntos analizados en yacimientos similares, como Castro Ventosa (DÍAZ ÁLVAREZ y GARÍN 1999). A la espera de poder realizar análisis antracológicos en futuras excavacio- 
nes, lo que se muestra a través de los restos óseos es la presencia de una economía parcialmente de tipo ganadero, si bien la presencia de otros materiales permite completar este cuadro económico.

\subsection{Otros materiales cerámicos: material constructivo y pesas de telar}

Dentro del material analizado de Valencia do Sil cabe mencionar la aparición de distintos fragmentos de material constructivo y algunas pesas de telar. Entre el primer grupo, se han documentado numerosos restos, normalmente muy fragmentados, tanto de tégulas (teja plana) como ímbrices (teja curva), que serían utilizados para los tejados y, en el caso de las tégulas, tal vez como solera. Por las excavaciones y restos de estructuras aún presentes en el yacimiento se puede deducir que las construcciones asociadas a su ocupación durante el período romano estaban hechas a base de mampuestos y sillarejo de cuarcita, lo que explicaría la ausencia de ladrillos macizos en el conjunto analizado. El uso de la tégula y de los ímbrices para las construcciones es una característica de las tipologías constructivas de época romana, si bien su uso perduró en el tiempo, llegando incluso hasta el siglo VII/VIII d.n.e., como se muestra en otros yacimientos de la meseta norte o de Portugal (CUESTA GÓMEZ, RAMOS, y PRATA 2018; TEJERIZO GARCÍA 2017).

En este sentido, y aunque no se trata de un material específicamente cerámico, hay que mencionar la documentación de estucos con restos de pintura localizados principalmente en la denominada "casa romana" por los excavadores. Este tipo de recubrimientos, si bien muy comunes en ámbitos como las villas tardoimperiales o las ciudades, es extremadamente raro en contextos fortificados (SASTRE BLANCO, FUENTES MELGAR, y CATALÁN RAMOS 2014). Esto subrayaría la capacidad económica y simbólica de los habitantes de Valencia do Sil y su posible carácter elitista.

Por último, cabe mencionar la aparición de pesas de telar, extremadamente comunes en los yacimientos de época romana. Tipológicamente muestran las características típicas de este tipo de materiales, con forma trapezoidal de barro macizo con un agujero perforado en la parte más alta (PÉREZ ROZAS 2017). Su aparición en Valencia do Sil demostraría la presencia de telares en el yacimiento y, por lo tanto, se reforzaría el carácter tanto doméstico como productivo del sitio, así como explicaría la presencia de oveja en el conjunto óseo para el aprovechamiento de la lana. Algunos estudios vinculan este tipo de materiales con las actividades de mantenimiento realizadas por las mujeres en las sociedades romanas y tardorromanas (SÁNCHEZ ROMERO 2005), lo que también mostraría una cierta división de las tareas en estas sociedades. Del mismo modo, cabe mencionar la documentación de recortes circulares de pizarra con agujero, que posiblemente fueran utilizados como pesas, de un telar o quizá para redes de pesca.

\subsection{Vidrios}

Se han podido documentar hasta 19 fragmentos de vidrio dentro del material analizado. Este número es extremadamente bajo para lo que suele ser habitual en este tipo de contextos (FUENTES DOMÍNGUEZ 1990). Así, es muy probable que el número original 
de fragmentos de vidrio exhumados fuera mucho mayor pero que debido a los procesos postdeposicionales, el tratamiento post-excavación o incluso los expolios posteriores hayan mermado la cantidad de este material.

Todos los fragmentos responden a vidrios de color verdoso típicos de época romana y tardorromana (ABÁSOLO ÁLVAREZ, CORTES, y MARCOS 2004; FUENTES DOMÍNGUEZ 1990). Únicamente fue posible reconocer un borde de una posible botella de labio vuelto y muy engrosado que, por lo fragmentado de la pieza, no pudo ser relacionado con ninguna forma específica.

\subsection{Material metálico y monedas}

Si bien en el inventario facilitado por el IEV se hace referencia a distintos materiales metálicos del yacimiento de Valencia do Sil que incluían anillos de bronce, sortijas, fíbulas y punzones así como en las distintas referencias al yacimiento se mencionan monedas, pocos son los materiales metálicos que han podido ser analizados en el conjunto revisado. Esto está muy posiblemente relacionado con el material que se separó de este conjunto a lo largo de las últimas dos décadas, que habría privilegiado los objetos metálicos de calidad frente al resto.

Dentro de los metales que han quedado en el conjunto analizado destacan, por su cantidad, los clavos, las puntas y las tachuelas. Ambos serían utilizados fundamentalmente dentro del ámbito doméstico, sobre todo para la techumbre y para los muebles de madera. En el caso de algunas tachuelas, estas podrían pertenecer a los calzados utilizados por los habitantes del asentamiento. El uso de calzado con tachuelas en época romana y postromana está ampliamente documentado, sobre todo en las necrópolis, dado que se enterraban con este tipo de vestimentas. Este es el caso, por ejemplo, de la necrópolis norte de La Olmeda (ABÁSOLO ÁLVAREZ, CORTES, y RODRÍGUEZ ARAGÓN 1997) o de A Lanzada (FARIÑA BUSTO 1975).

Por otro lado, cabe hacer mención a varias escorias de metal, muy posiblemente de hierro. Se documentaron casi $5 \mathrm{~kg}$. de escoria asociados a Valencia do Sil, algunos fragmentos de gran tamaño. Esto sugeriría la producción de hierro dentro del yacimiento y, muy posiblemente, la cercana presencia de un horno con respecto a la zona excavada, como se han documentado en otros contextos como El Castillón, en Zamora (SASTRE BLANCO y FUENTES MELGAR 2011).

Dentro del material que se llevaron de Valencia do Sil, sin duda uno de los más significativos fue el probablemente gran conjunto de monedas localizadas en el yacimiento. A través de distintas informaciones orales y por las referencias de los pocos artículos publicados (ver más arriba), la presencia de monedas en el yacimiento debió de ser muy significativa. Sin embargo, en el conjunto analizado no se localizó ninguna moneda, por lo que sólo contamos con esas pocas referencias indirectas, además del artículo publicado por F. Bouza sobre la moneda vinculada con una posible ceca de época sueva instalada en el yacimiento. Con respecto a esta moneda albergamos ciertas dudas sobre su adscripción al yacimiento, tanto por el resto de material documentado del sitio como por los patrones conocidos para la moneda de época sueva en este entorno (CEBREIRO ARES 
2012; DÍAZ MARTÍNEZ 2011; PLIEGO VÁZQUEZ 2009). Es significativo, por ejemplo, que en el cercano yacimiento de Penadominga, donde sí hay documentado un importante tesorillo de monedas, no apareciera ninguna moneda de época sueva (CEPEDA 1993). Queda, sin embargo, esta hipótesis sin resolver hasta realizar más excavaciones en el contexto de Valencia do Sil. Por lo demás, las únicas referencias a monedas en Valencia do Sil son las recogidas anteriormente, vinculadas a emisiones que recorren un largo período entre mediados del siglo II y el siglo IV d.n.e. Sin duda, un dato de extremado interés pero sujeto a los mismos condicionantes que el resto del material analizado, sobre todo teniendo en cuenta los amplios períodos de uso de la moneda romana, como se ha mostrado en el caso de yacimientos similares, como en Viladonga (TEJERIZO GARCÍA, et al. 2019).

\section{Algunas consideraciones sobre el yacimiento de Valencia do Sil}

El yacimiento de Valencia do Sil es, sin duda, un yacimiento de extraordinario interés, si bien sometido a una compleja historia de intervenciones, que ha dejado una importante cantidad de material que, hasta ahora, permaneció inédito. Creemos que con este primer acercamiento al material asociado al sitio que aquí presentamos se aportará una valiosa información para el conocimiento no sólo del yacimiento sino también de los períodos tardoimperiales y suevo en la comarca de Valdeorras que, salvo por algunas escasas publicaciones, era apenas conocido (RODRÍGUEZ COLMENERO, et al. 2009). Lamentablemente, la historiografía del sitio hace que este análisis se vea limitado por dos razones: la primera es que el material carece de contextos estratigráficos, lo que impide realizar una secuencia del sitio y, por lo tanto, limita la posibilidad de historiarlo convenientemente. La segunda es que, como ya se comentó, parte del material, posiblemente el de mayor calidad, fue separado y en paradero desconocido en la actualidad. A pesar de ello, el análisis ha permitido extraer algunas conclusiones de interés así como algunas preguntas a resolver en futuras intervenciones.

La primera es en relación a la posible secuencia de ocupación del yacimiento. En base al análisis cerámico realizado, nuestra hipótesis es que el yacimiento tiene una ocupación principal centrada entre los siglos IV y VI d.n.e., si bien es difícil por el momento ser más precisos. Aunque existen algunos elementos concretos que podrían indicar la presencia de una ocupación anterior, como es un único fragmento altoimperial de sigillata o parte del numerario asociado al yacimiento, el grueso del material exhumado parece ser más coherente con las cronologías propuestas, sobre todo a tenor de su comparación con otros conjuntos arqueológicos mejor conocidos, como pueden ser los de Castro Ventosa, Viladonga, los contextos tardíos de Lugo o Braga (FERNÁNDEZ FERNÁNDEZ, CARVALHO, ANDRÉ, COSTA, y TERESO 2018; TEJERIZO GARCÍA, et al. 2019).

En cualquier caso, no se puede descartar por el momento una ocupación anterior. La propuesta de una ocupación del sitio entre el siglo IV y VI d.n.e. es sólo una hipótesis que deberá ser corroborada con una intervención arqueológica estratigráfica que permita, mediante la combinación de diversas técnicas (C14, análisis estratigráfico, termolumi- 
niscencia...), secuenciar con mayor precisión el sitio. En cualquier caso, de ser cierta esta hipótesis, Valencia do Sil sería el primer asentamiento fortificado de ocupación tardía ocupado ex novo -esto es, sin fases anteriores de época prehistórica o altoimperial- estudiado arqueológicamente en el noroeste de la península ibérica, lo que aportaría una información muy interesante para entender este fenómeno en el contexto de la desarticulación del Imperio Romano (TEJERIZO GARCÍA y CANOSA BETÉS 2018).

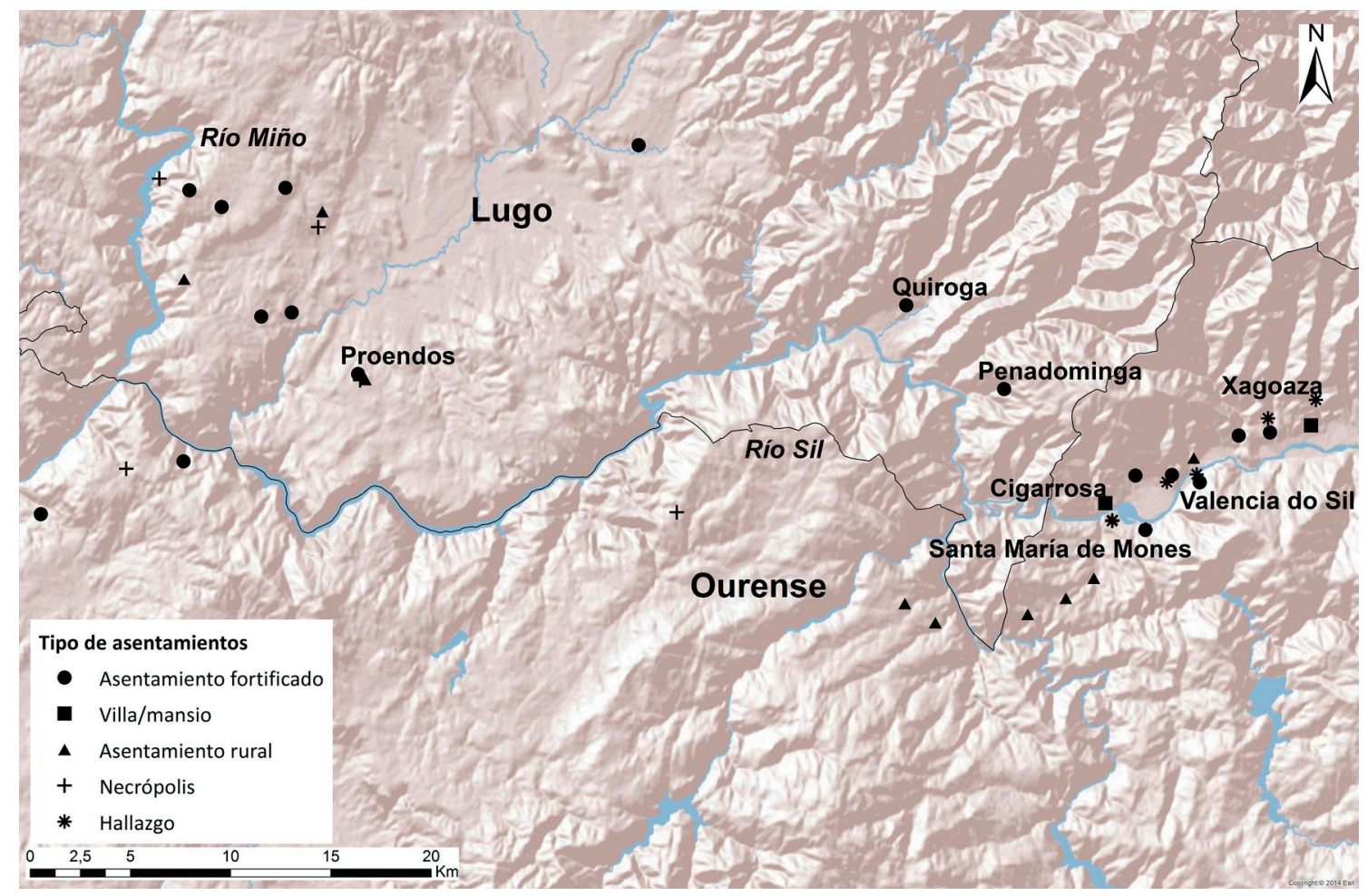

Figura 12. Yacimientos de época tardorromana y sueva en el entorno de Valdeorras.

Por otro lado, el análisis del material arqueológico muestra claramente la relevancia de Valencia do Sil en la articulación del territorio en ese período (Figura 12). En primer lugar, la presencia de materiales como las ánforas -si bien todavía dudosa en su identificación específica- mostraría la presencia de una red comercial que, en nuestra opinión, se desarrollaba a lo largo del río Sil. Las recientes excavaciones en la ciudad de Vigo muestran la vitalidad del comercio atlántico en este período que, posiblemente, tuviera su desarrollo también en el interior de la antigua Gallaecia precisamente a través de las redes fluviales (FERNÁNDEZ FERNÁNDEZ 2014; FERNÁNDEZ PEREIRO, et al. 2017). Igualmente, la presencia de la Via Nova en los entornos de este yacimiento es un elemento muy significativo a tener en cuenta, ya que podría funcionar en este período, al igual que ya lo hacía con anterioridad, como un nexo de unión entre la meseta norte y los territorios del noroeste peninsular.

En segundo lugar, el interés arqueológico de Valencia do Sil queda reflejada en la presencia, más que significativa, de escorias de hierro, que sugeriría la potencial producción de elementos de este metal en el propio sitio. Esto ha sido reconocido en otros sitios de 
gran relevancia en el contexto tardoimperial y suevo, como es el yacimiento de Viladonga o Castro Ventosa (ARIAS VILAS, et al. 2013; TEJERIZO GARCÍA y VIGIL-ESCALERA GUIRADO 2017). De hecho, algunos autores como J.C. Sánchez vinculan sitios como Valencia do Sil a la revitalización de la minería en la zona tras la desarticulación del Imperio Romano y la inestabilidad asociada a las llamadas "invasiones bárbaras" (SÁNCHEZ PARDO 2010). Esta hipótesis sería extremadamente interesante de plantear en futuras intervenciones en el sitio.

En tercer lugar, hay que entender el sitio de Valencia do Sil en el contexto de la comarca de Valdeorras y de la cuenca del Sil. Los diversos trabajos llevados en la zona muestran la significativa concentración de asentamientos fortificados siguiendo el curso del río, que contrasta con la situación de otras regiones del norte y noroeste peninsular (FERNÁNDEZ PEREIRO, et al. 2017; RODRÍGUEZ COLMENERO, et al. 2009). Sitios como Penadominga, Santa María de Mones, Quiroga, Proendos, O Castrillón, etc. muestran evidencias de ocupación en esta horquilla en torno a la cuarta y la quinta centuria, lo que señalaría la presencia de una red articulada de este tipo de centros que, muy posiblemente, esté relacionada con la acción de las élites postromanas y su agencia en el paisaje tras la desarticulación del Imperio Romano (TEJERIZO GARCÍA y CANOSA BETÉS 2018). Esta agencia podría también rastrearse a través de la presencia en el territorio de varios restos asociados a edificios de culto cristiano de gran suntuosidad, que incluiría, por ejemplo, el posible capitel de época visigoda vinculado a Valencia do Sil, así como el Crismón de Quiroga o los canceles localizados en la cercana parroquia de Petín (RODRÍGUEZ COLMENERO 1977), entre otros. Todos estos objetos señalarían la presencia en el paisaje de una élite eclesiástica que, posiblemente, tuviera una estrecha relación con este tipo de enclaves fortificados a lo largo del curso del río Sil. No hay que olvidar tampoco que esta zona se englobaría teóricamente dentro del lugar de Carioca, mencionado en el Parochiale Suevum (SÁNCHEZ PARDO 2014), que podría indicar una cohesión territorial articulada a través de la conexión de este tipo de enclaves y de edificios.

Estas son algunas de las ideas y preguntas surgidas tras el análisis del material arqueológico de Valencia do Sil. Sin embargo, muchas de ellas tienen que plantearse en forma de hipótesis a corroborar en futuras campañas arqueológicas que pasan, con seguridad, con una excavación sistemática y estratigráfica que permita contrastar estas preguntas científicamente. En este sentido, el enclave de Valencia do Sil es, de nuevo, excepcional, dada la espectacular conservación de las estructuras de época tardorromana y sueva. No hay duda de que este sitio es un enclave único para profundizar en el conocimiento de un período llamado "oscuro" pero que lentamente se empieza a iluminar.

\section{Bibliografía}

ABASCAL PALAZÓN, J. M. 1986. La cerámica pintada romana de tradición indígena en la Península Ibérica. Centros de producción, comercio y tipología. Alicante. Universidad de Alicante.

ABÁSOlO ÁlVAREZ, J. A., CORTES, J., y MARCOS, F.-J. 2004. Los recipientes de vidrio de las Necrópolis de La Olmeda. Palencia. Diputación de Palencia. 
ABÁSOLO ÁlVAREZ, J. A., CORTES, J., y RODRÍGUEZ ARAGÓN, F. P. 1997. La necrópolis Norte de la Olmeda. Palencia. Diputación Provincial de Palencia.

ADROHER AUROUX, A. M., CARRERAS MONFORT, C., DE ALMEIDA, R., FERNÁNDEZ FERNÁNDEZ, A., MOLINA VIDAL, J., y VIEGAS, C. 2016. "Registro para la cuantificación de cerámica arqueológica: estado de la cuestión y una nueva propuesta. Protocolo de Sevilla (PRCS/14)”. Zephyrus, LXXVIII, pp. 87-110. DOI: https://doi.org/10.14201/zephyrus20167887110

ALCORTA IRASTORZA, E. J. 2001. Lucus Augusti (vol. II): cerámica común de cocina y mesa hallada en las excavaciones de la ciudad. A Coruña. Fundación Pedro Barrié de la Maza.

ALCORTA IRASTORZA, E. J., y BARTOLOMÉ ABRAIRA, R. 2012. Muestras de cerámica engobada romana de producción local de Lucus Augusti (Lugo). En D. Bernal Casasola y A. Ribera I Lacomba (eds.). Cerámicas hispanorromanas II. Producciones regionales. Cádiz: Universidad de Cádiz, pp. 699-724.

ARIAS VILAS, F., DURÁN FUENTES, M. C., BASTOS BERNÁRDEZ, D., y VARELA ARIAS, E. 2013. Museo do Castro de Viladonga (Castro de Rei, Lugo). Santiago de Compostela. Xunta de Galicia.

BOUZA BREY, F. 1953. "La ceca suevo visigoda de Valencia del Sil”. Zephyrus, IV, pp. 417-427.

BUSTAMANTE ÁLVAREZ, M. 2016. "La cerámica pintada romana de tradición indígena en el territorio de Extremadura”. SPAL, 25, pp. 183-207. DOI: https://doi.org/10.12795/spal.2016i25.07

CEBREIRO ARES, F. 2012. Dificultades que plantea el estudio de la historia monetaria sueva. En F. Cebreiro Ares (ed.), Introducción a la historia monetaria de Galicia (s. II a.C. - XVII d.C.). A Coruña: Labirinto de Paixóns, pp. 31-63

CEPEDA, J. J. 1993. "Monedas procedentes del castro de Penadominga (Bendollo, Quiroga. Lugo)". Numisma, 232, pp. 91-107.

CUESTA GÓMEZ, F., RAMOS, T., y PRATA, S. 2018. Empezar la casa por el tejado: las cerámicas de cobertura en los contextos altomedievales del territorio de Castelo de Vide (Portugal). En I. Martín Viso, P. Fuentes Melgar, J. C. Sastre Blanco y R. Catalán Ramos (eds.). Cerámicas altomedievales en Hispania y su entorno (s.V-VIII). Madrid: Glyphos, pp. 137-158.

DÍAZ ÁLVAREZ, I., y GARÍN, A. 1999. "Estudio de los materiales arqueológicos de Castro Ventosa". Estudios Bercianos, 25, pp. 74-95.

DÍAZ MARTÍNEZ, P. D. L. C. 2011. El Reino Suevo (411-585). Tres Cantos. Akal, D.L.

DORREGO MARTÍNEZ, F., y RUBIERO DA PENA, A. M. 1998. "Consideracións sobre os temas decorativos na cerámica castrexa de Viladonga”. CROA. Boletín da Asociación de Amigos do Museo do Castro de Viladonga, 8, pp. 21-28.

FARIÑA BUSTO, F. 1975. Excavación de A Lanzada (Sanxenxo-Pontevedra). Informe preliminar de la campaña. Museo de Pontevedra, T.29.

FERNÁNDEZ FERNÁNDEZ, A. 2008. Cerámicas del mundo castrexo del NO Peninsular. Problemática y principales producciones. En D. Casasola Bernal y A. Ribera I Lacomba (eds.). Cerámicas hispanorromanas. Un estado de la cuestión. Cádiz: Universidad de Cádiz, pp. 221-243.

FERNÁNDEZ FERNÁNDEZ, A. 2014. El comercio tardoantiguo (ss.IV-VII) en el Noroeste peninsular a través del registro cerámico de la ría de Vigo. Oxford. Archaeopress.

FERNÁNDEZ FERNÁNDEZ, A., y BARTOLOMÉ ABRAIRA, R. 2016. Cerámicas tardoantiguas en el noroeste de la Península (Galicia y norte de Portugal): entra la importación y el artesanado local/ regional. En J. A. Quirós Castillo y A. Vigil-Escalera (eds.). Bilbao: Universidad del País Vasco, pp. 69-111.

FERNÁNDEZ FERNÁNDEZ, A., CARVALHO, P. C., ANDRÉ, C., COSTA, M., y TERESO, S. 2018. Contextos cerámicos de época alto y bajo imperial provenientes de La Torre Velha-Castro de Avelas (Bragança, Portugal) Rei Cretariae Romanae Fautorum. Acta 45. Bonn, pp. 71-81.

FERNÁNDEZ PEREIRO, M., TEJERIZO GARCÍA, C., RODRÍGUEZ GONZÁLEZ, C., LIXÓ GÓMEZ, C., y CARVAJAL CASTRO, Á. 2017. "Asentamentos fortificados no interior da Gallaecia en época tardoimperial e sueva (séc. IV-VI): un achegamento a partir de varios casos de estudo”. Gallaecia, 36, pp. 129-162. DOI: https://doi.org/10.15304/gall.36.5104 
FERNÁNDEZ RODRÍGUEZ, C. 200o. Los macromamíferos en los yacimientos arqueológicos del noroeste peninsular: un estudio económico. Tesis Doctoral. Santiago de Compostela. Universidad de Santiago de Compostela.

FUENTES DOMÍNGUEZ, Á. 1990. "Los vidrios de las necrópolis de la Meseta: ensayo preliminar de clasificación". Cuadernos de prehistoria y arqueología, 17, pp. 169-202.DOI: https://doi. org/10.15366/cupauam1990.17.010

GONZÁLEZ-RUIBAL, A. 2006-2007. Galaicos. Poder y comunidad en el Noroeste de la Península Ibérica (120o a.C-5o d.C) (Vol. 18). A Coruña. Museo Arqueolóxico e Histórico de A Coruña.

GRAU SOLOGESTOA, I. 2015. "Livestock management in Spain from Roman to post-medieval times: a biometrical analysis of cattle, sheep/goat and pig”. Journal of Archaeological Science, 54, pp. 123-134.DOI: https://doi.org/10.1016/j.jas.2014.11.038

JUAN TOVAR, L. C. 2012. Las cerámicas imitación de sigillata en el occidente de la Península Ibérica durante el siglo V d.C. En D. Bernal Casasola y A. Ribera I Lacomba (eds.). Cerámicas hispanorromanas II. Producciones regionales. Cádiz: Universidad de Cádiz, pp. 97-129.

LEMONNIER, P. 1986. "The study of material culture today: toward an anthropology of technical systems”. Journal of anthropological archaeology, 5, pp.147-186 DOI: https://doi.org/10.1016/02784165(86)90012-7

LÓPEZ QUIROGA, J. 2004. El final de la antigüedad en la Gallaecia: la transformación de las estructuras de poblamiento entre Miño y Duero (siglos Val X). La Coruña. Fundación Pedro Barrie de la Maza.

LÓPEZ QUIROGA, J., y LOVELLE, M. R. 1999. "Castros y castella tutiora de época sueva en Galicia y norte de Portugal: ensayo de inventario y primeras propuestas interpretativas”. Hispania Antiqua, XXIII, pp. 355-374.

MARÍN SUÁREZ, C. 2012. "La cerámica de la Edad del Hierro en el sector centro-occidental cantábrico”. Munibe, 63, pp. 165-198.

MARTÍN VISO, I., FUENTES MELGAR, P., SASTRE BLANCO, J. C., y CATALÁN RAMOS, R. 2018. Cerámicas altomedievales en Hispania y su entorno (s.V-VIII). Madrid. Glyphos.

MÉNDEZ REVUELTA, C. 1974-1975. "Fragmentos de terra sigillata hispánica del Castelo de Valencia do Sil (Ourense)". Cuadernos de Estudios Gallegos, 87-89, pp. 297-303.

MORAIS, R., MORILLO CERDÁN, Á., DJAOUI, D., y PEREIRA, P. 2015. Novos paradigmas de investigação: ânforas de fundo plano e cerâmicas comuns utilizadas no transporte de produtos. En A. Martínez Salcedo, M. Esteban Delgrado y E. J. Alcorta Irastorza (eds.). Cerámicas de época romana en el norte de Hispania y en Aquitania. Producción, comercio y consumo entre el Duero y el Garona. Madrid: La Ergástula, pp. 45-58.

OZCÁRIZ GIL, P. 2010. "Grafitos epigráficos sobre cerámica romana en Navarra”. Cuadernos de Arqueología, 18, pp. 331-354.

PAZ PERALTA, J. A. 1991. Cerámica de mesa romana de los siglos III al VI d.C en la provincia de Zaragoza. Zaragoza. Institución Fernando el Católico.

PAZ PERALTA, J. A. 2013. La vajilla de cerámica hispánica tardía gris y naranja en Asturica Augusta (Astorga, León). Conjunto C Ex Officina Hispana. Cuadernos de la SECAH, 1. Madrid: La Ergástula, pp. 217-256.

PÉREZ ROZAS, Á. 2017. "A produción téxtil na cultura castrexa: as fusaiolas do Castro de Viladonga (Castro de Rei, Lugo)". CROA. Boletín da Asociación de Amigos do Museo do Castro de Viladonga, 27, pp. 32-51.

PLIEGO VÁZQUEZ, R. 2009. La moneda visigoda (2 vols.). Sevilla. Universidad de Sevilla.

REY CASTIÑEIRA, J. 2010. A produción cerámica. En J. Rey Castiñeira, E. Abad Vidal, N. Calo Ramos, C. Candamo Bueno, M. Comesaña Cortegoso, M. Martín Seijo, G. Meijide Cameselle, N. Pena Monteagudo, I. Picón Platas, A. Rico Rey, C. Rodríguez Rellan y A. Teira Brion (eds.). Formigueiros. Análise da cultura material. Santiago de Compostela: Universidade de Santiago de Compostela,

RIGOIR, J. 1968. "Les sigillées paléochrétiennes grises et orangées". Gallia, XXVI, pp. 177-244. DOI: https://doi.org/10.3406/galia.1968.2496 
RISCO, V. 1920. Provincia de Orense. Geografía General del Reino de Galicia. Barcelona.

ROCA ROUMENS, M., y FERNÁNDEZ GARCÍA, M. I. (eds.). 1999. Terra Sigillata Hispánica. Centros de fabricación y producciones altoimperiales. Jaén/Málaga. Universidad de Jaén/Universidad de Málaga.

RODRÍGUEZ COLMENERO, A. 1977. Galicia meridional romana. Bilbao.

RODRÍGUEZ COLMENERO, A., FERRER SIERRA, S., y GARCÍA TATO, I. 2009. Priorato de Xagoaza (Valdeorras, Ourense). Bande. Fundación Aquae Querquennae - Via Nova.

RODRIGUEZ RESINO, Á. 2006. Del Imperio Romano a la Alta Edad Media. Arqueología de la Tardoantigüedad en Galicia (siglos V-VIII). Noia. Toxosoutos.

SÁNCHEZ PARDO, J. C. 2010. "Castros y aldeas galaicorromanas: sobre la evolución y transformación del poblamiento indígena en la Galicia romana”. Zephyrus, LXV, pp. 129-148.

SÁNCHEZ PARDO, J. C. 2012. Castros, castillos y otras fortificaciones en el paisaje sociopolítico de Galicia (siglos IV-XI). En J. Quirós Castillo y J. M. Tejado Sebastián (eds.). Los castillos altomedievales en el noroeste de la Península Ibérica. Bilbao: Universidad del País Vasco, pp. 29-56.

SÁNCHEZ PARDO, J. C. 2014. "Organización eclesiástica y social en la Galicia tardoantigua. Una perspectiva geográfico-arqueológica del parroquial suevo”. Hispania Sacra, 134, pp. 439-48o.DOI: https://doi.org/10.3989/hs.2014.058

SÁNCHEZ ROMERO, M. 2005. Arqueología y género. Granada. Universidad de Granada.

SASTRE BLANCO, J. C., y FUENTES MELGAR, P. 2011. Late roman metallurgy in Castro of El Castillón (Santa Eulalia de Tábara, Zamora). En D. Hernández De La Fuente (ed.), New perspectives on Late Antiquity. Cambridge: Cambridge Scholars Publishing, pp. 229-244.

SASTRE BLANCO, J. C., FUENTES MELGAR, P., y CATALÁN RAMOS, R. 2014. Las fortificaciones en la tardoantigüedad. Élites y articulación del territorio (siglos V-VIII d.C.). Madrid. La Ergástula.

SOTO ARIAS, P. 1993. "Estudio de un asentamiento romano ligado a la vía XVIII en el Valle de Valdeorras (Ourense)”. Minius, II-III, pp. 53-81.

TEJERIZO GARCÍA, C. 2016a. Construyendo la casa por los cimientos: consideraciones acerca de la cerámica de la primera Alta Edad Media en la parte central de la cuenca del Duero. En J. A. Quirós Castillo y A. Vigil-Escalera (eds.). La cerámica de la Alta Edad Media en el cuadrante noroeste de la Península Ibérica (siglos $V$-X). Bilbao: Universidad del País Vasco, pp. 229-254.

TEJERIZO GARCÍA, C. 2016b. Construyendo la casa por los cimientos: consideraciones acerca de la cerámica de la primera Alta Edad Media en la parte central de la cuenca del Duero. En J. A. Quirós Castillo y A. Vigil-Escalera (eds.). Bilbao: Universidad del País Vasco, pp. 229-254.

TEJERIZO GARCÍA, C. 2017. Arqueología de las sociedades campesinas en la cuenca del Duero durante la Primera Alta Edad Media. Bilbao. Universidad del País Vasco.

TEJERIZO GARCÍA, C., y CANOSA BETÉS, J. 2018. "Power, control and social agency in post-roman northern Iberia: an archaeological analysis of hillfort occupations". Journal of Medieval Iberian Studies, 10.3, pp. 295-323 DOI: https://doi.org/10.1080/17546559.2018.1504383

TEJERIZO GARCÍA, C., RODRÍGUEZ GONZÁLEZ, C., y FERNÁNDEZ PEREIRO, M. 2018. "Materiais cerámicos tardíos (ss. IV-VI d.C.) no castro de Viladonga”. CROA. Boletín da Asociación de Amigos do Museo do Castro de Viladonga, 28, pp. 36-52. DOI:https://doi.org/10.12795/spal.2019.i28.22

TEJERIZO GARCÍA, C., RODRÍGUEZ GONZÁLEZ, C., y FERNÁNDEZ PEREIRO, M. 2019. “¿Continuidad o discontinuidad en los castros del noroeste? Una revisión del yacimiento de Viladonga (Castro de Rei, Lugo)". SPAL, 28.2, pp. 279-313. https://doi.org/10.12795/spal.2019.i28.22

TEJERIZO GARCÍA, C., y VIGIL-ESCALERA GUIRADO, A. 2017. "Castro Ventosa y La Cabeza de Navasangil: una revisión de sus secuencias de ocupación y del fenómeno de los asentamientos fortificados altomedievales". Nailos, 4, pp. 129-161.

VAN DER LEEUW, S. E. 1977. Towards a study of the economics of pottery making. En B. L. Van Beek y R. W. Brandt (eds.). Ex Horreo. Amsterdam: Universiteit van Amsterdam, pp. 68-85.

VEGAS, M. 1973. Cerámica común romana del Mediterráneo occidental. Barcelona. Universidad de Barcelona. 
VEIGA ROMERO, A. M. 2009. “Los mosaicos de A Cigarrosa. Historia de un hallazgo”. Museo arqueolóxico provincial de Ourense.

VIGIL-ESCALERA, A. 2003. Cerámicas tardorromanas y altomedievales de Madrid. En L. Caballero Zoreda, P. Mateos y M. Retuerce (eds.). Cerámicas tardorromanas y altomedievales en la Península Ibérica Vol. XXVIII: Anejos de AEspA, pp. 371-387.

VIGIL-ESCALERA, A. 2006. "La cerámica del período visigodo en Madrid”. Zona arqueológica, 8, pp. 705-716.

VIGIL-ESCALERA, A. 2013. "Las últimas producciones de TSHT en el interior peninsular”. Ex officina hispania. Cuadernos de la SECAH, 1, pp. 11-24.

VIGIL-ESCALERA, A. 2015. Los primeros paisajes altomedievales en el interior de Hispania. Registros campesinos del siglo quinto d.C. Bilbao. Universidad del País Vasco.

VIGIL-ESCALERA, A., y QUIRÓS CASTILLO, J. A. 2016. La cerámica de la Alta Edad Media en el cuadrante noroeste de la Península Ibérica (siglos $V$-X). Bilbao. Universidad del País Vasco.

VIGO GARCÍA, A. 2017. Intervención Arqueolóxica en Os Castros (Mondoñedo, Lugo). Memoria técnica inédita. 